\title{
Study of Aerosol Influence on Nighttime Land Surface Temperature Retrieval Based on Two Methods
}

\author{
Caixia Gao, ${ }^{1}$ Enyu Zhao, ${ }^{2}$ Chuanrong Li, ${ }^{1}$ Yonggang Qian, ${ }^{1}$ Lingling $\mathrm{Ma},{ }^{1}$ Lingli Tang, \\ Xiaoguang Jiang, ${ }^{2}$ and Hongyuan Huo ${ }^{2}$ \\ ${ }^{1}$ Key Laboratory of Quantitative Remote Sensing Information Technology, Academy of Opto-Electronics, \\ Chinese Academy of Sciences, Beijing 100094, China \\ ${ }^{2}$ University of Chinese Academy of Sciences, Beijing 100094, China
}

Correspondence should be addressed to Caixia Gao; caixiagao2010@hotmail.com and Yonggang Qian; qianyg2000@163.com

Received 11 November 2014; Accepted 11 February 2015

Academic Editor: Klaus Dethloff

Copyright (C) 2015 Caixia Gao et al. This is an open access article distributed under the Creative Commons Attribution License, which permits unrestricted use, distribution, and reproduction in any medium, provided the original work is properly cited.

\begin{abstract}
The aim of this study is to evaluate the aerosol influence on LST retrieval with two algorithms (split-window (SW) method and a four-channel based method) using simulated data under typical conditions. The results show that the root mean square error (RMSE) decreases to approximately $2.3 \mathrm{~K}$ for SW method and $1.5 \mathrm{~K}$ for four channel based method when VZA $=60^{\circ}$ and visibility $=$ $3 \mathrm{~km}$; an RMSE would be increased by approximately $1.0 \mathrm{~K}$ when visibility varies from $3 \mathrm{~km}$ to $23 \mathrm{~km}$. Moreover, a detailed sensitivity analysis under a visibility of $3 \mathrm{~km}$ and $23 \mathrm{~km}$ is performed in terms of uncertainties of land surface emissivity (LSE), water vapor content (WVC), and instrument noise, respectively. It is noted that the four-channel based method is more sensitive to LSE than SW method, especially for dry atmosphere; LST error caused by a WVC uncertainty of $20 \%$ is within $1.5 \mathrm{~K}$ for SW method and within $0.8 \mathrm{~K}$ for four-channel based method; the instrument noise would introduce LST error with a maximum standard deviation of $0.5 \mathrm{~K}$ and $0.04 \mathrm{~K}$ for the four-channel based method and SW method, respectively.
\end{abstract}

\section{Introduction}

As the direct driving force in the exchange of long-wave radiation and turbulent heat fluxes at the surface-atmosphere interface, land surface temperature (LST) is a key parameter in the research of land surface processes at global or regional scale, energy, and water cycle $[1,2]$. LST has high spatial and temporal variation [3] and the traditional in situ measurement methods can only provide LST at point or local scales [4], so that it is unreliable to acquire LST at global scale by interpolation method. Remote sensing is a unique way of measuring LST at regional and global scales [5], and in the last twenty years, various infrared sensors onboard satellite have been launched successfully, such as Moderate Resolution Imaging Spectroradiometer (MODIS), Advanced Very High Resolution Radiometer (AVHRR), Advanced Along-Track Scanning Radiometer (AASTR), and Spinning Enhanced Visible and Infrared Imager (SEVIRI), among others. Meanwhile, the LST retrieval technology from remote sensing data made a great progress, and various methods have been proposed, such as single channel method $[6,7]$, split-window (SW) method [8-12], temperature emissivity separation (TES) method [13], and multichannel method [14, 15], among others. However, these algorithms just provide a multichannel correction for attenuation arising from molecular water vapor absorption under clear skies, and aerosol effect on LST retrieval is overlooked [16].

Atmospheric aerosols comprise a dispersed system of small solid and liquid particles suspended in air for varying periods of time and transported by vertical and horizontal wind currents, frequently to great distances. Even for clear skies, the particulates affect the heating or cooling of the atmosphere through scatter and absorption of energy, depending on the chemical and physical properties of the particles [17]. Therefore, there are some previous investigations into the problem on sea surface temperature [16, 18-23]. However, because the uncertainty of accurately determining the land surface emissivity (LSE) is still crucial for improving 
LST retrieval algorithms, few studies have considered reducing the influences of different aerosol types and loadings on the retrieval of LST from remote sensing data.

The transmittance for the middle infrared (MIR) channel in atmosphere window is more stable with less change to the surface temperature, and most values are above 0.8 [15]. In consideration of this, a four-channel based method for LST algorithm using 2 thermal infrared (TIR) channels and 2 MIR channels has been developed [15]. Since the aerosol size range covers more than five orders of magnitude, from $10 \mathrm{~nm}$ to several hundred micrometers [17] and the aerosol effect decreases with the increase of wavelength, MIR channels are more sensitive to aerosol particles than TIR channels. Therefore, in this study, a detailed analysis on the performance of this method under typical conditions is investigated in terms of aerosol, LSE, water vapor content (WVC), instrument noise, using simulated airborne hyperspectral scanner (AHS) data, which has multiple TIR and MIR channels providing an excellent opportunity for evaluating the algorithms' performances; meanwhile, an intercomparison with a two-TIR channel $(11 \mu \mathrm{m}$ and $12 \mu \mathrm{m})$ based SW method is performed. In addition, in this study, to avoid the interference of solar direct radiation, only the algorithms for nighttime LST retrieval are analyzed.

In this paper, Section 2 shows the basic theory in infrared spectrum. Section 3 describes the data characteristics, atmospheric and aerosol characteristics in AHS channels for LST inversion. Section 4 presents the simulated data. Section 5 gives the results and discussions. Finally, the conclusions and summary are drawn in Section 6.

\section{Methodology}

2.1. Radiative Transfer Model. Based on the radiative transfer theory and assuming a cloud-free atmosphere under local thermodynamic equilibrium, the infrared spectral radiance $L\left(\theta_{v}, T, \lambda\right)$ at the top of atmosphere (TOA) for a viewing zenith angle (VZA), $\theta_{v}$, can be expressed as [24]

$$
\begin{aligned}
& L\left(\theta_{v}, T, \lambda\right) \\
& \quad=R\left(\theta_{v}, T_{g}, \lambda\right) \tau\left(\theta_{v}, \lambda\right)+R_{\mathrm{atm} \uparrow}\left(\theta_{v}, \lambda\right)+R_{\mathrm{atm} \uparrow}^{s}\left(\theta_{v}, \lambda\right)
\end{aligned}
$$

with

$$
\begin{aligned}
& R\left(\theta_{v}, T_{g}, \lambda\right) \\
&= \varepsilon\left(\theta_{v}, \lambda\right) B\left(T_{s}, \lambda\right)+\left(1-\varepsilon\left(\theta_{v}, \lambda\right)\right) \\
& \cdot\left(R_{\text {atm } \downarrow}(\lambda)+R_{\text {atm } \downarrow}^{s}(\lambda)\right)+\rho\left(\theta_{v}, \theta_{s}, \varphi, \lambda\right) E_{\text {sun }}\left(\theta_{s}, \lambda\right),
\end{aligned}
$$

where $T$ is the TOA brightness temperature (BT), $T_{g}$ is the BT for surface-leaving radiance, and $\varepsilon\left(\theta_{v}, \lambda\right)$ and $\tau\left(\theta_{v}, \lambda\right)$ are the directional spectral emissivity and the total atmospheric spectral transmittance at a VZA of $\theta_{v}$, respectively; $R_{\mathrm{atm} \uparrow}\left(\theta_{v}, \lambda\right)$ and $R_{\mathrm{atm} \uparrow}^{s}\left(\theta_{v}, \lambda\right)$ represent the upwelling atmospheric spectral radiance and the upwelling diffusion radiance that results from the scattering of solar radiance at a VZA of $\theta_{v}$, respectively; $T_{s}$ is the LST; $R_{\mathrm{atm} \downarrow}(\lambda)$ and $R_{\mathrm{atm} \downarrow}^{s}(\lambda)$ represent the downwelling hemispheric atmospheric spectral irradiance and the downwelling diffusion irradiance that results from the scattering of solar radiation divided by $\pi$, respectively; $\rho\left(\theta_{v}, \theta_{s}, \varphi, \lambda\right)$ is the bidirectional spectral reflectivity; $\theta_{s}$ is the solar zenith angle and $\varphi$ is the relative azimuth angle between the view azimuth angle and the solar azimuth angle; and $E_{\text {sun }}\left(\theta_{s}, \lambda\right)$ is the direct solar spectral irradiance at ground level. For the spectral radiance in the TIR channels and the nighttime measurements in the MIR channels, $E_{\text {sun }}\left(\theta_{s}, \lambda\right), R_{\mathrm{atm} \uparrow}^{s}\left(\theta_{v}, \lambda\right)$, and $R_{\mathrm{atm} \downarrow}^{s}(\lambda)$ can be neglected without loss of accuracy.

2.2. LST Retrieval Method. The TOA radiance measured by infrared sensors is influenced by surface properties (LST and LSE) and atmosphere. To retrieve LST physically, the LSE for each channel must be known and is acquired by classification. Under a given VZA, the SW method and the four-channel based method for each surface type can be expressed as follows [15]:

(i) two-TIR channel based SW method (denoted as Algorithm 1):

$$
\begin{aligned}
\operatorname{LST}_{i}= & a_{0}(i)+a_{1}(i) T_{11}+a_{2}(i)\left(T_{11}-T_{12}\right) \\
& +a_{3}(i)\left(T_{11}-T_{12}\right)^{2},
\end{aligned}
$$

where $\mathrm{LST}_{i}$ is the LST for the $i$ th IGBP surface types and $T_{11}$ and $T_{12}$ are the TOA BT of the adjacent thermal channels. These parameters $a_{0}(i), a_{1}(i), a_{2}(i)$, and $a_{3}(i)$ are the regression coefficients for the $i$ th surface type for nighttime LST retrievals.

(ii) The four-channel based method (denoted as Algorithm 2):

$$
\begin{aligned}
\mathrm{LST}_{i}= & b_{0}(i)+b_{1}(i) T_{11}+b_{2}(i)\left(T_{11}-T_{12}\right) \\
& +b_{3}(i)\left(T_{11}-T_{12}\right)^{2}+b_{4}(i) T_{\mathrm{MIR} 1} \\
& +b_{5}(i) T_{\mathrm{MIR} 2}+b_{6}(i) T_{\mathrm{MIR} 1}^{2}+b_{7}(i) T_{\mathrm{MIR} 2}^{2}
\end{aligned}
$$

where $T_{\mathrm{MIR} 1}$ and $T_{\mathrm{MIR} 2}$ are the TOA BT of the two MIR channels in atmospheric window, respectively. These parameters $b_{0}(i)-b_{7}(i)$ are the regression coefficients for the $i$ th surface type for nighttime LST retrievals.

In this study, we mainly analyze the performances of the two LST retrieval methods affected by aerosol for two typical surface types (soil and grass surfaces) under dry (WVC: $0-1.5 \mathrm{~g} / \mathrm{cm}^{2}$ ) and wet atmosphere (WVC: $4.0-5.5 \mathrm{~g} / \mathrm{cm}^{2}$ ), respectively.

\section{Optimal Channels Selection}

The main problem in surface temperature retrieval from space is the modification of the surface radiation on its 


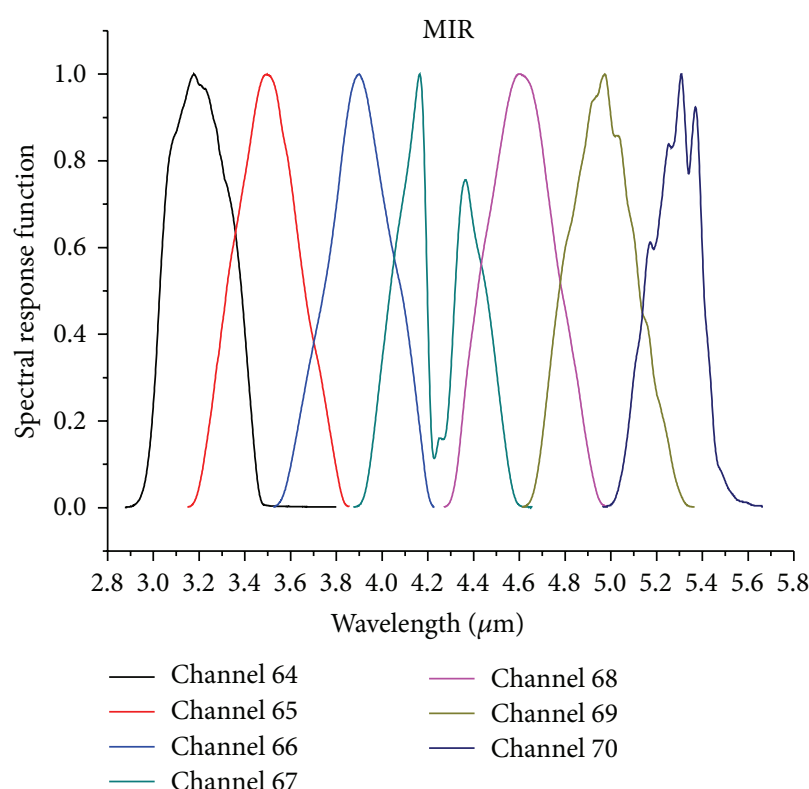

(a)

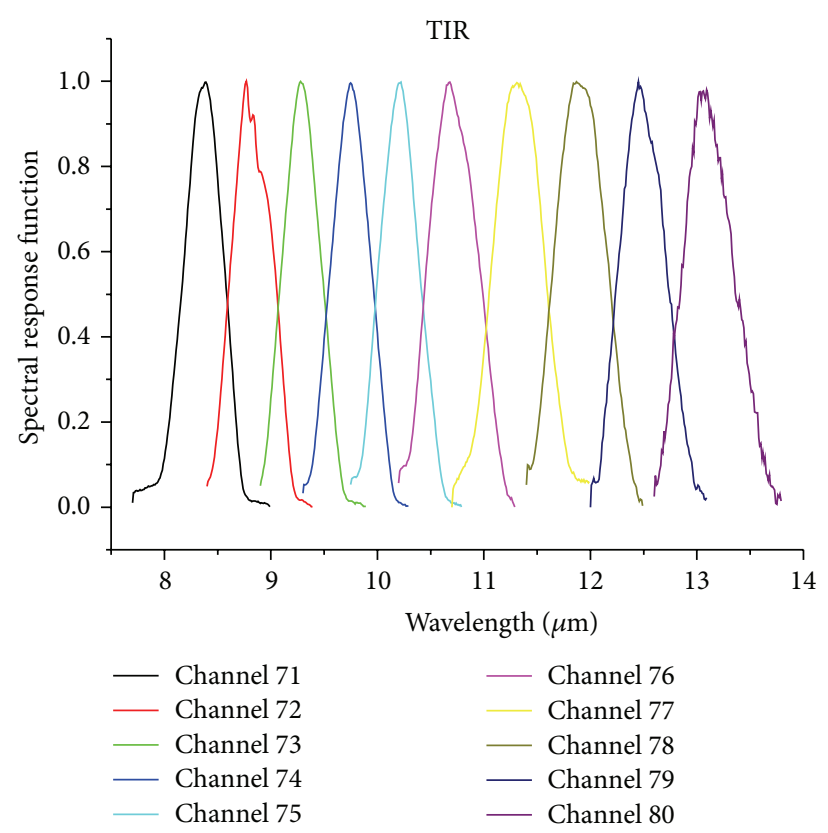

(b)

FIgURE 1: Spectral response functions for MIR and TIR channels of AHS.

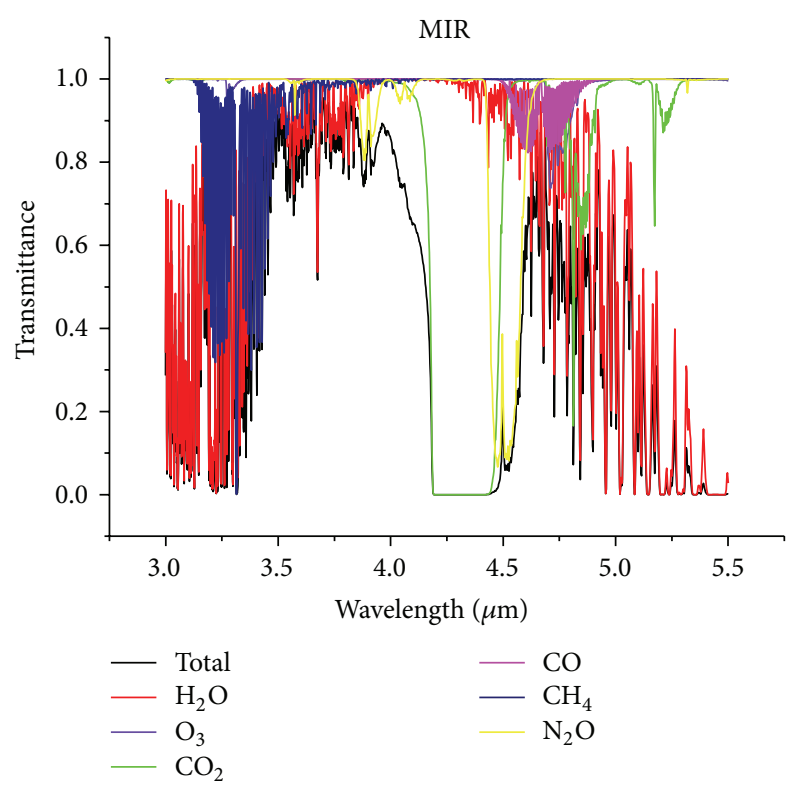

(a)

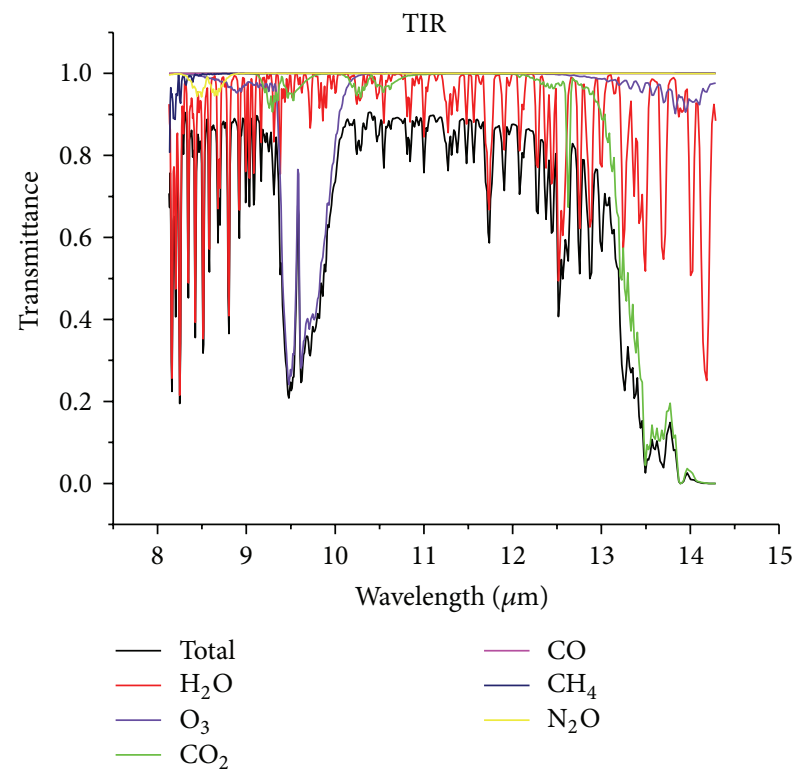

(b)

FIgURE 2: Atmospheric molecular $\left(\mathrm{CO}_{2}, \mathrm{O}_{3}, \mathrm{H}_{2} \mathrm{O}, \mathrm{CO}, \mathrm{N}_{2} \mathrm{O}\right.$, and $\left.\mathrm{CH}_{4}\right)$ transmittance in MIR and TIR spectrum.

way through the atmosphere and the contribution of the atmosphere itself to the final signal measured by the sensor [25]. The content of atmospheric constituents as water vapor, ozone, and uniformly mixed gases $\left(\mathrm{CO}_{2}, \mathrm{CO}, \mathrm{CH}_{4}, \mathrm{~N}_{2} \mathrm{O}\right.$, and $\mathrm{O}_{2}$ ) as well as the temperature profile strongly affecting the accuracy of LST retrieval. In this section, the atmospheric characteristics in AHS channels are analyzed for retrieving LST with optimal channels.
3.1. AHS Description. The AHS is an imaging line-scanner radiometer, acquiring images in 80 spectral channels covering the visible and near infrared (VNIR, 20 channels), short wave infrared (SWIR, 43 channels), MIR (7 channels), and TIR (10 channels) spectral ranges. AHS has an instantaneous field of view (IFOV) of $2.5 \mathrm{mrad}$ and a FOV of $\pm 45^{\circ}$ [26]. The spectral characteristics for the MIR and TIR channels are shown in Figure 1. 


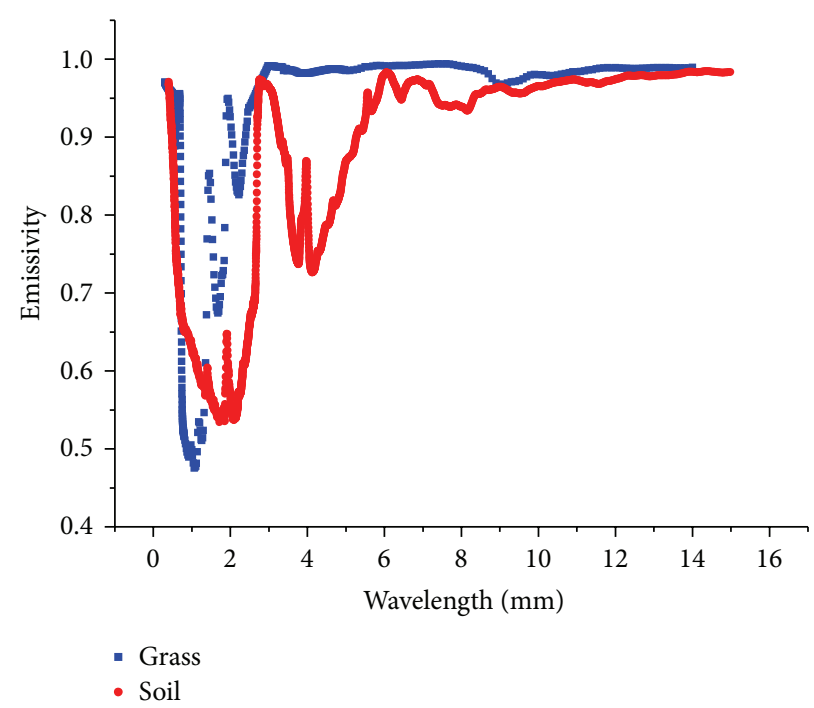

FIGURE 3: The emissivity of soil and grass obtained from ASTER Spectral library.

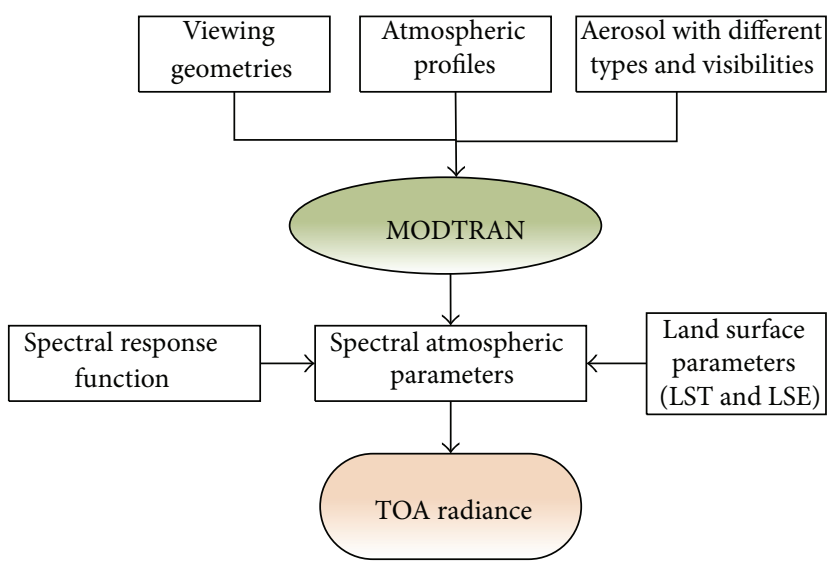

FIGURE 4: Flowchart for simulating TOA radiance.

3.2. Atmosphere Characteristics in AHS Channels. Absorption by atmospheric molecules is a key parameter impacting the radiance measured by sensors; therefore, it is essential to analyze the absorption characteristics of atmospheric molecular in MIR and TIR spectrum for selecting the optimal channels for LST retrieval efficiently. As an example, the absorption properties of several atmospheric gases $\left(\mathrm{H}_{2} \mathrm{O}\right.$, $\mathrm{CO}_{2}, \mathrm{O}_{3}, \mathrm{CO}, \mathrm{N}_{2} \mathrm{O}$, and $\mathrm{CH}_{4}$ ) for an US standard atmosphere in MIR and TIR spectrum including urban aerosol are displayed in Figure 2. It is noted that the MIR range is divided by the several absorption subranges mainly induced by $\mathrm{N}_{2} \mathrm{O}$ and $\mathrm{CO}_{2}$ [25]. The ozone absorption splits the thermal infrared region into two parts such that one is more transparent than the other [25] (see Figure 2). In both infrared ranges, water vapor is the primary absorber and therefore substantially responsible for the shape of the total transmission. For MIR range, it is obvious that there exist two atmospheric windows of approximately $3.3 \sim 4.2 \mu \mathrm{m}$ and $4.8 \sim 5.1 \mu \mathrm{m}$, and a strong absorption of $\mathrm{CO}_{2}$ is presented approximately from $4.2 \mu \mathrm{m}$ to $4.4 \mu \mathrm{m}$, which is almost blind to land surface; $\mathrm{CH}_{4}$ molecular appears strong absorption approximately from $3.2 \mu \mathrm{m}$ to $3.5 \mu \mathrm{m}$, and less absorption can be found in other spectrum; there exists strong absorption of $\mathrm{N}_{2} \mathrm{O}$ approximately from $4.4 \mu \mathrm{m}$ to $4.6 \mu \mathrm{m}$; CO molecular has a relatively weak absorption approximately from $4.5 \mu \mathrm{m}$ to $4.8 \mu \mathrm{m}$; other atmospheric molecules have relatively high transmittance in MTR spectrum. For TIR range, besides $\mathrm{O}_{3}$ absorption band ranging from 9 to $10 \mu \mathrm{m}, \mathrm{H}_{2} \mathrm{O}$ mainly contributes to the total transmittance.

In consideration of the locations of AHS spectral channels (see Figure 1) and the absorption characteristics of atmospheric molecular (see Figure 2), it is noted that AHS channel $64(\mathrm{CH} 64)$ and channel $65(\mathrm{CH} 65)$ are affected seriously by the strong absorption of $\mathrm{CH}_{4}$; AHS channel $67(\mathrm{CH} 67)$ is influenced by a strong absorption by $\mathrm{CO}_{2}$ and $\mathrm{N}_{2} \mathrm{O}$; AHS channel $69(\mathrm{CH} 69)$ and channel $70(\mathrm{CH} 70)$ are strongly affected by $\mathrm{H}_{2} \mathrm{O}$. Furthermore, since AHS CH64 and AHS $\mathrm{CH} 70$ are too close to the edges of $3 \sim 5 \mu \mathrm{m}$ atmosphere 


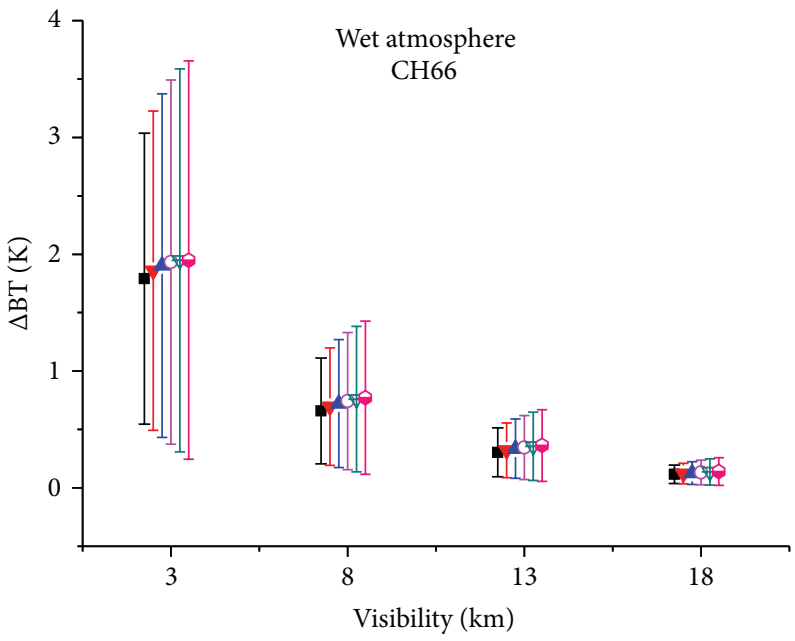

(a)

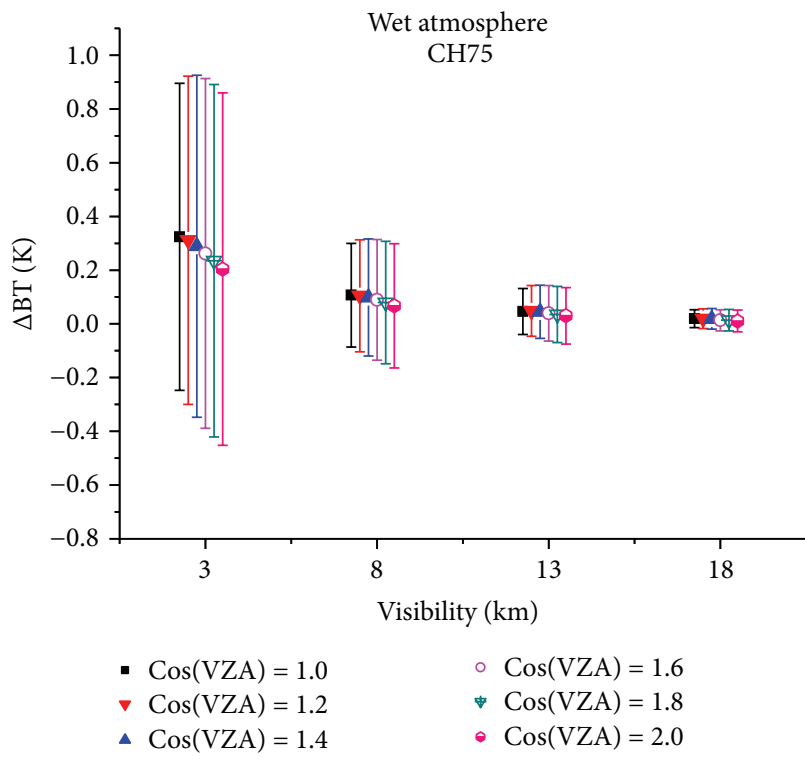

(c)

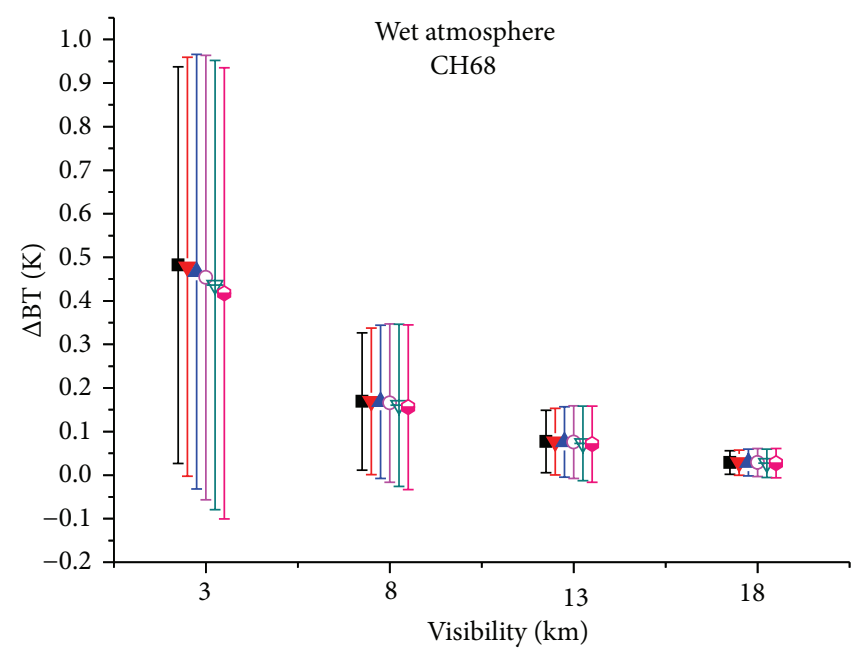

(b)

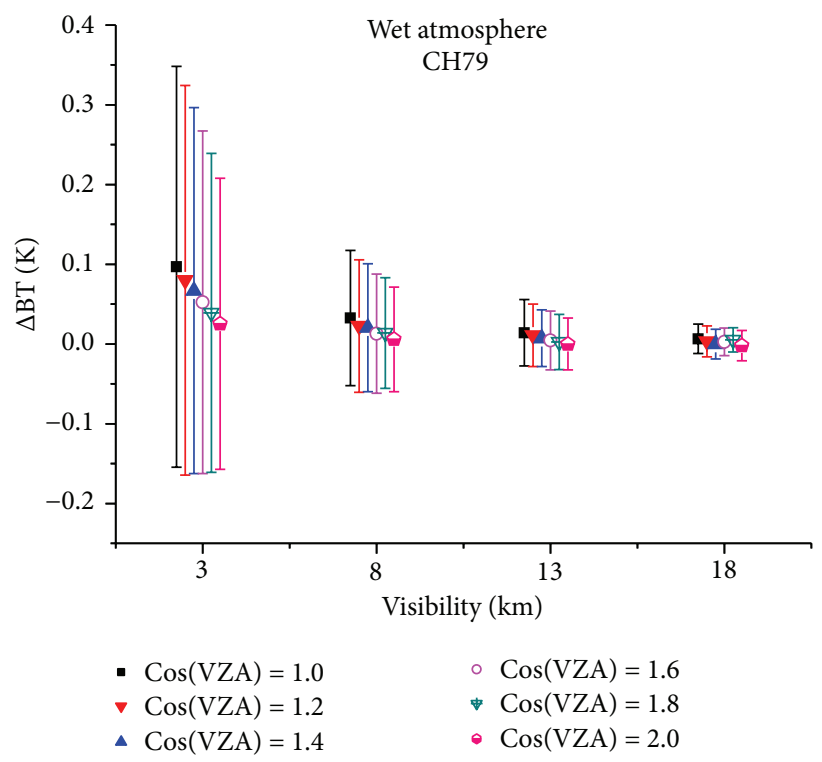

(d)

FIGURE 5: Differences $(\triangle \mathrm{BT}$ ) between aerosol-contaminated TOA BT (visibility $=3,8,13,18 \mathrm{~km}$, resp.) and that aerosol-free TOA BT (visibility $=23 \mathrm{~km}$ ) under wet atmosphere including urban aerosol type. The deviation bars are centred on the mean of the temperature difference (denoted by the symbols in the figure), and the half-length of each bar is equal to the standard deviation of $\Delta \mathrm{BT}$.

window and are usually rather noisy [26], the two channels AHS CH66 and $\mathrm{CH} 68$ weakly by atmospheric absorption are selected.

In addition, for TIR spectrum, AHS channels $71(\mathrm{CH} 71)$ and 80 (CH80) show the highest atmospheric absorption; channels 75 (CH75) to 79 (CH79) are located in the atmospheric window 10 12.5 $\mu \mathrm{m}$; channel $74(\mathrm{CH} 74)$ is located in the region of the ozone absorption. In consideration of the combined effects of atmospheric molecular absorption and previous studies on LST retrieval for AHS data using SW method [27], AHS CH75 and CH79 are excellent channels for LST retrieval.

\section{Data Simulation}

In order to determine the coefficients $a_{0}(i) \sim a_{3}(i)$ and $b_{0}(i) \sim b_{7}(i)$, a serial of AHS data under different atmospheric and surface conditions are simulated with the atmospheric radiative transfer code MODTRAN 4. In this study, the atmospheric profiles are extracted from the Thermodynamic Initial Guess Retrieval (TIGR) dataset at Laboratoire de Météorologie Dynamique [28, 29], and 705 clear-sky profiles with relative humidity at one of levels lower than $90 \%$ are extracted from TIGR dataset, covering a wide range of bottom atmospheric temperature $\left(T_{a}: 250 \sim 310 \mathrm{~K}\right)$ and atmospheric WVC $\left(0.06 \sim 5.39 \mathrm{~g} / \mathrm{cm}^{2}\right)$. 


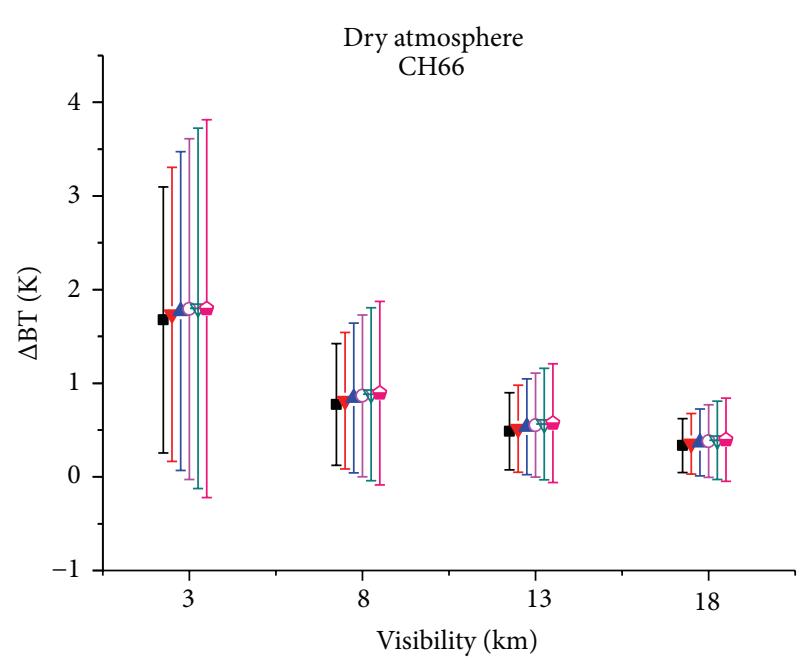

(a)

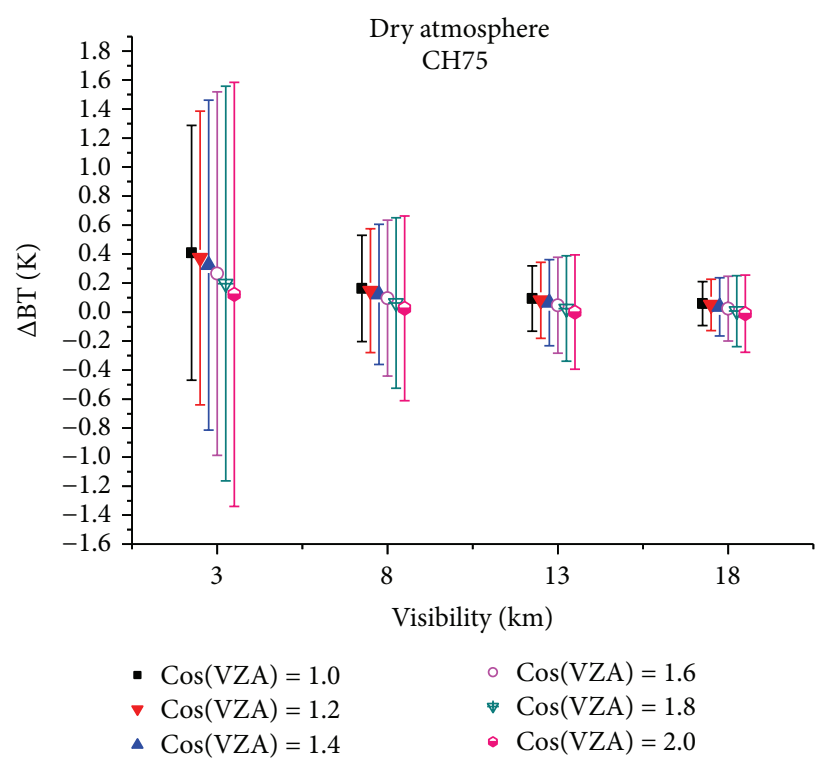

(c)

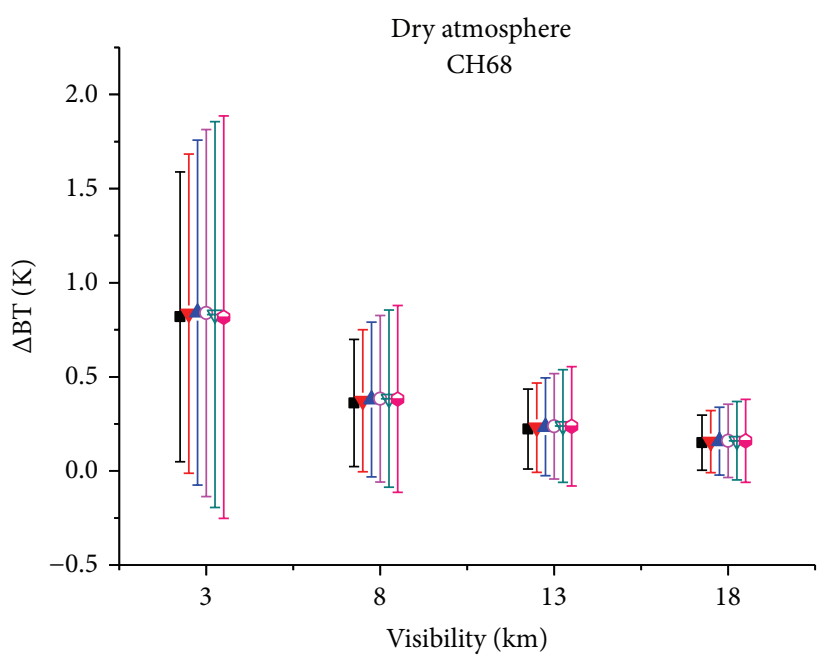

(b)

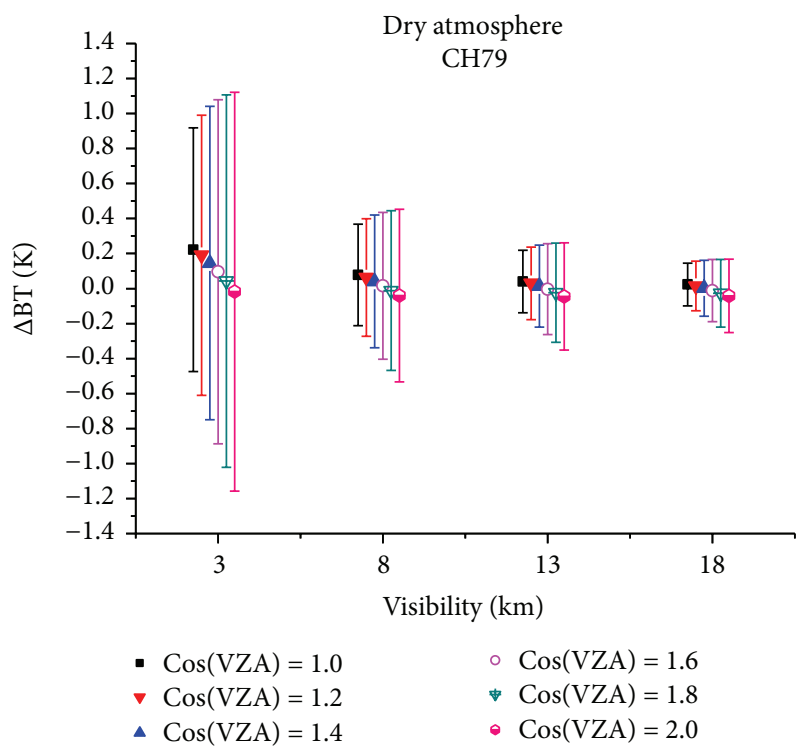

(d)

FIGURE 6: The same legend as Figure 5, but for dry atmosphere.

To make the simulation more representatives, for analyzing the aerosol effect on LST retrieval over urban area, three types of aerosol, namely, rural, urban, and tropospheric aerosol [30], with visibility varying from 3 to $23 \mathrm{~km}$ with a step of $5 \mathrm{~km}$ are included, and the Mie theory is employed for the aerosol scattering. LST varies from $T_{a}-15 \mathrm{~K}$ to $T_{a}+5 \mathrm{~K}$ in step of $5 \mathrm{~K}$ for $T_{a}$ from $250 \mathrm{~K}$ to $310 \mathrm{~K}\left(T_{a}\right.$ is the atmospheric temperature in the first boundary layer of the selected atmosphere profiles). In addition, the emissivity from ASTER Spectral library is used in this study, which includes spectra of rocks, minerals, lunar soils, terrestrial soils, manmade materials, meteorites, vegetation, snow, and ice covering the visible to thermal infrared wavelength region $(0.4 \sim 15.4 \mu \mathrm{m})$ (http://speclib.jpl.nasa.gov/). As an example, the spectrum for soil and grass, used in this simulation, is shown in Figure 3. Furthermore, to account for angular effects, a total of 6 VZAs at a height of $100 \mathrm{~km}\left(0^{\circ}, 33.56^{\circ}\right.$, $44.42^{\circ}, 51.32^{\circ}, 56.25^{\circ}$, and $60^{\circ}$ ) are used in this simulation. Therefore, for a certain type of land surface, with these qualified atmospheric profiles, various aerosols, and VZAs as MODTRAN input parameters, the spectral atmospheric parameters, such as atmospheric transmittance, downwelling radiance, and upwelling radiance, can be acquired, and then the TOA radiance or BT is subsequently generated with the aid of land surface parameters (LST and LSE) and the channel spectral response function (see Figure 4).

Similar to LST retrieval schemes proposed by Wan and Dozier [31], for each VZA, the WVC and LST are divided into several tractable subranges for improving LST retrieval accuracy. In this paper, the LST is divided into five subranges with an overlap of $5 \mathrm{~K}$, that is, <280 K, 275 295 K, 290 $310 \mathrm{~K}, 305 \sim 325 \mathrm{~K}$, and $>320 \mathrm{~K}$, and WVC is divided into 


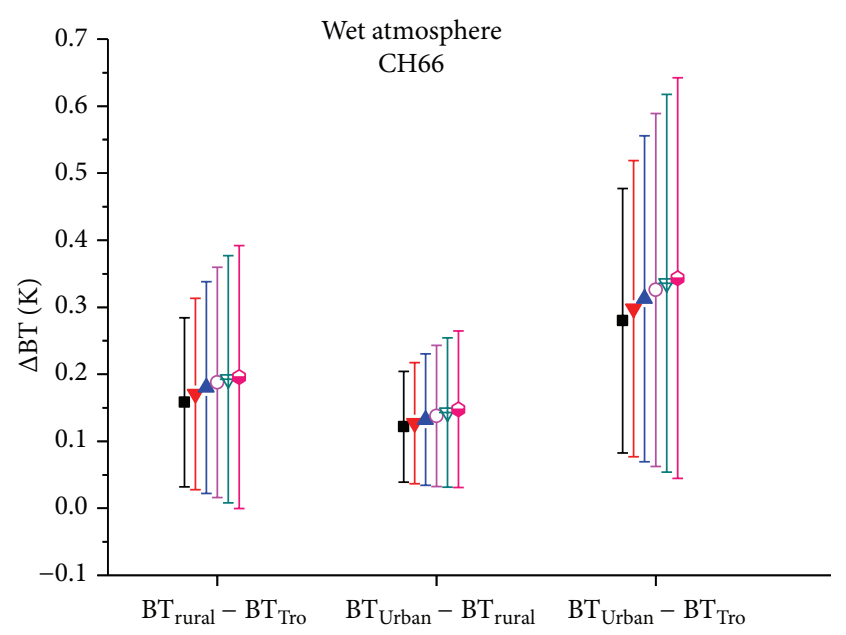

(a)

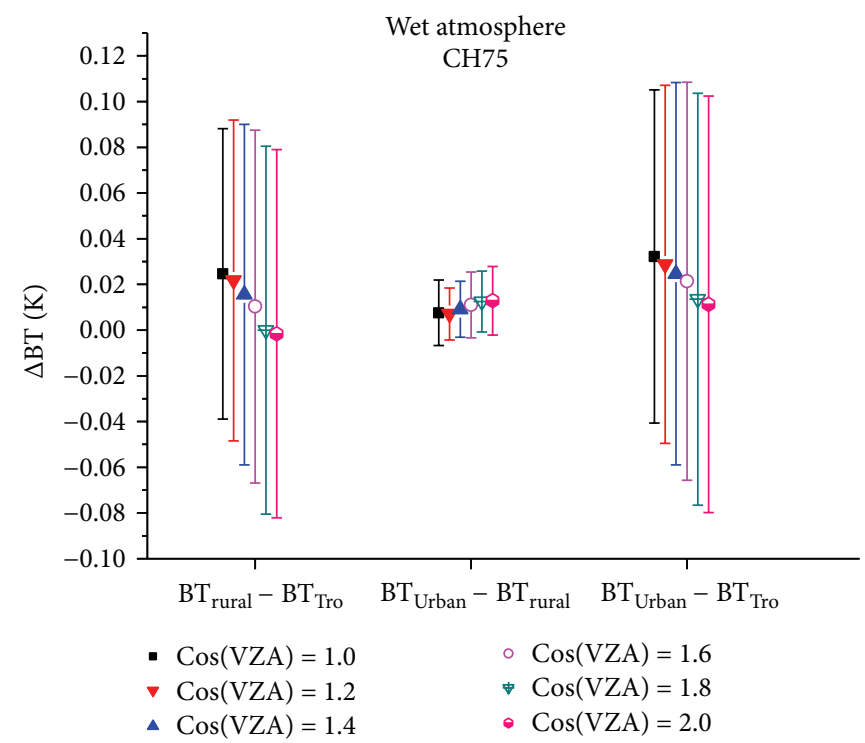

(c)

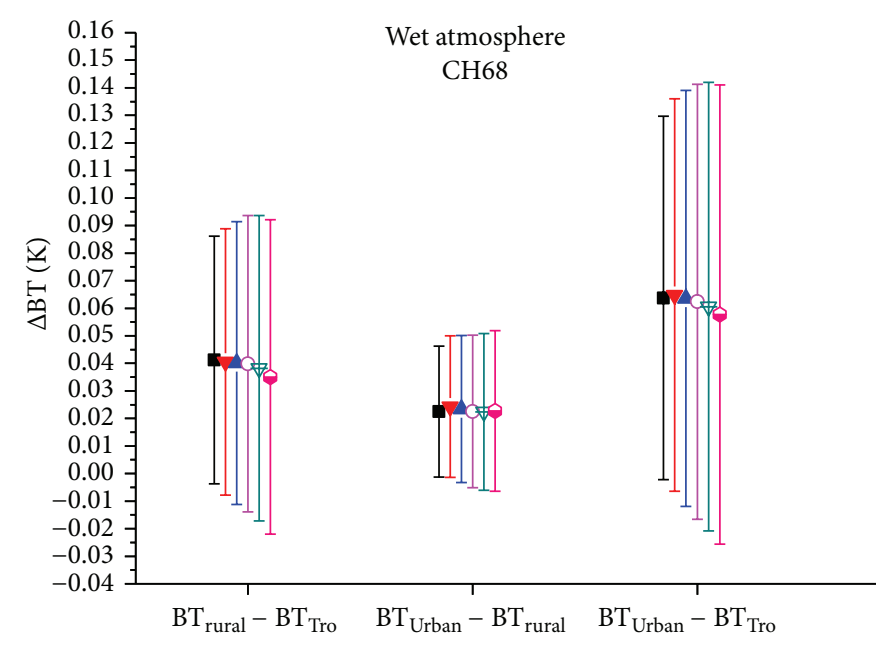

(b)

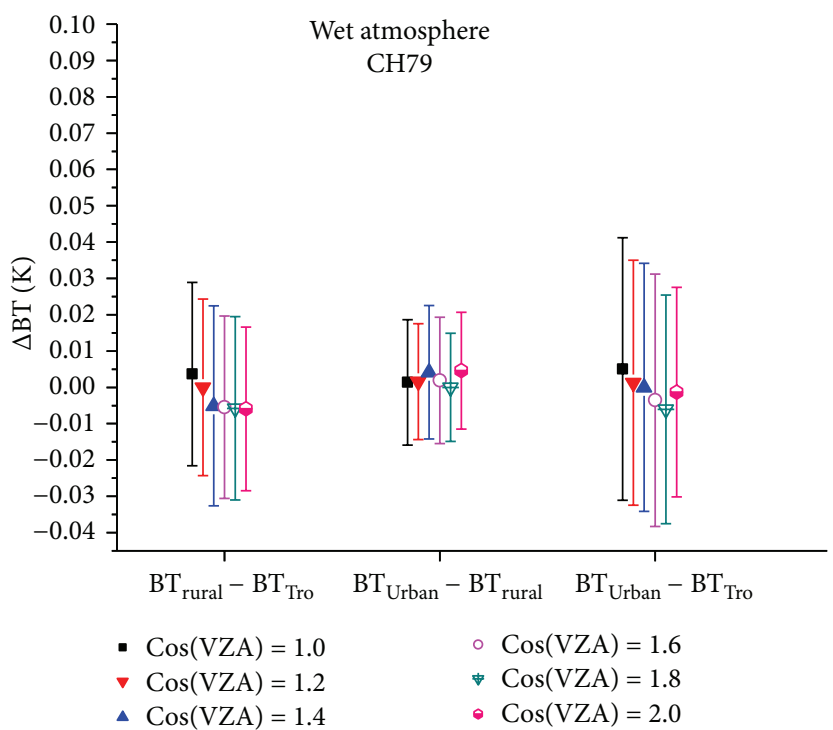

(d)

FIgURE 7: TOA BT difference caused by different aerosol type under wet atmosphere for soil surface.

five subranges with an overlap of $0.5 \mathrm{~g} / \mathrm{cm}^{2}$, that is, $0 \sim$ $1.5 \mathrm{~g} / \mathrm{cm}^{2}, 1.0 \sim 2.5 \mathrm{~g} / \mathrm{cm}^{2}, 2.0 \sim 3.5 \mathrm{~g} / \mathrm{cm}^{2}, 3.0 \sim 4.5 \mathrm{~g} / \mathrm{cm}^{2}$, and $4.0 \sim 5.5 \mathrm{~g} / \mathrm{cm}^{2}$. For each land surface, the corresponding coefficients $a_{0}(i) \sim a_{3}(i)$ and $b_{0}(i) \sim b_{7}(i)$ for each subrange can therefore be determined by the statistical regression (Levenberg-Marquardt method) with these simulated data.

\section{Results}

5.1. LST Retrieval under Aerosol Contaminated Condition. For LST retrieval, it is customary to express channelintegrated TOA radiance as BT, which is a coupling of atmosphere and land surface information and could be attenuated by the aerosol existing in the atmosphere, producing an effect on LST retrieval. In this paper, we begin exploring the effects of aerosol on TOA BT using radiative transfer simulations in terms of aerosol optical depth (AOD) (it is also expressed as visibility in this paper) and aerosol types; then the LST retrieval accuracy and uncertainty analysis under different AOD conditions for the two methods are analyzed systematically, with an aim of investigating the performances of the methods, especially under the aerosol contaminated skies.

5.1.1. Aerosol Effect on TOA BT. The magnitude of aerosolinduced attenuation in the IR depends on a number of factors, the more important ones being (1) AOD (or visibility), (2) the effective temperatures (vertical profile) of the gaseous and particulate absorbing layers, (3) the particle size distribution, and (4) particle chemical composition. The latter two provide information about the aerosol attenuation mechanism which cannot be inferred objectively from AOD value and is depicted as aerosol types. 

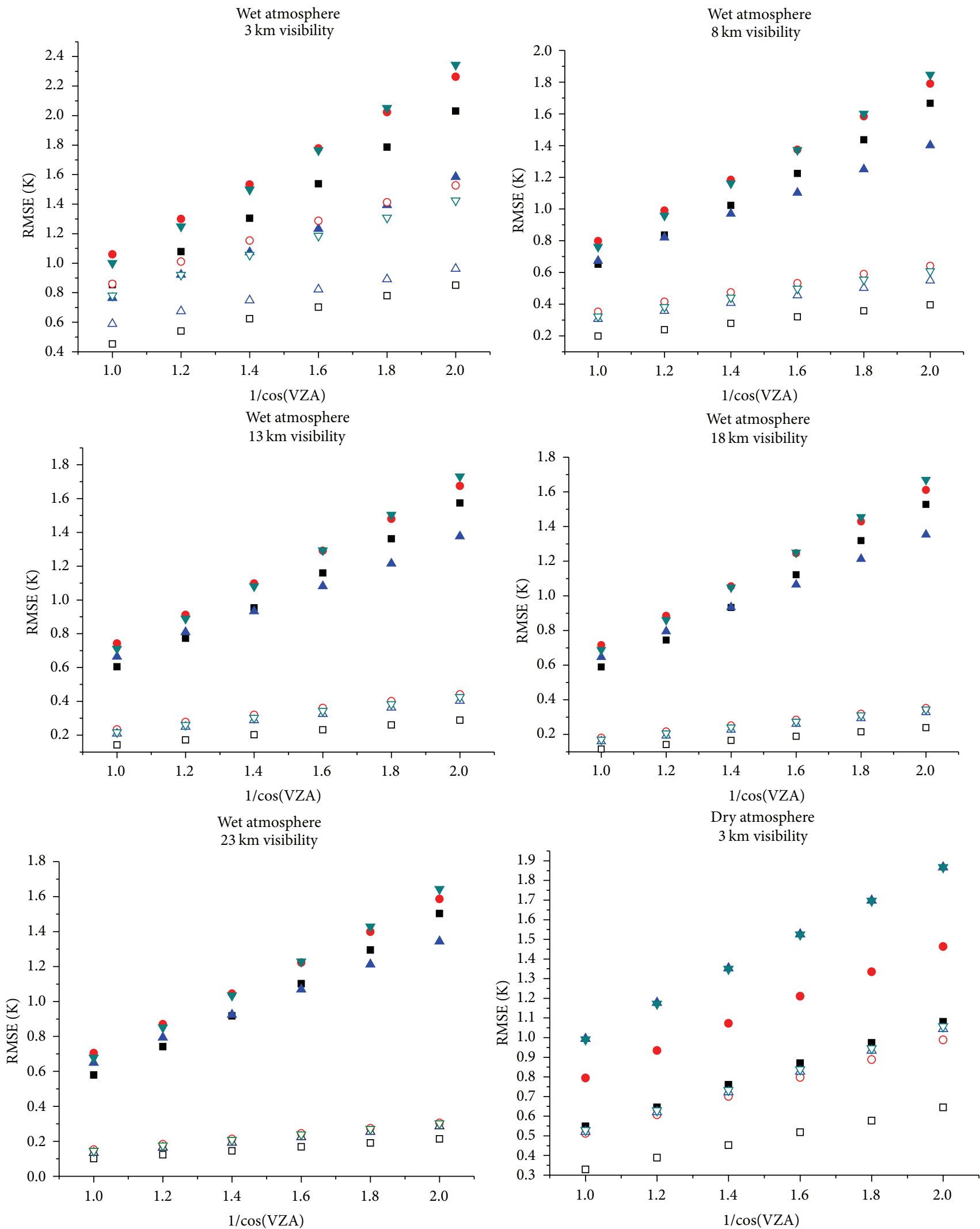

- $\square 295 \mathrm{~K}<\mathrm{LST}<315 \mathrm{~K} \Delta \triangle 255 \mathrm{~K}<\mathrm{LST}<285 \mathrm{~K}$

- $\circ 280 \mathrm{~K}<\mathrm{LST}<300 \mathrm{~K} \nabla \nabla 255 \mathrm{~K}<\mathrm{LST}<315 \mathrm{~K}$

- $\square 295 \mathrm{~K}<\mathrm{LST}<315 \mathrm{~K} \Delta \triangle 255 \mathrm{~K}<\mathrm{LST}<285 \mathrm{~K}$

- $0280 \mathrm{~K}<\mathrm{LST}<300 \mathrm{~K} \nabla \nabla 255 \mathrm{~K}<\mathrm{LST}<315 \mathrm{~K}$

Figure 8: Continued. 

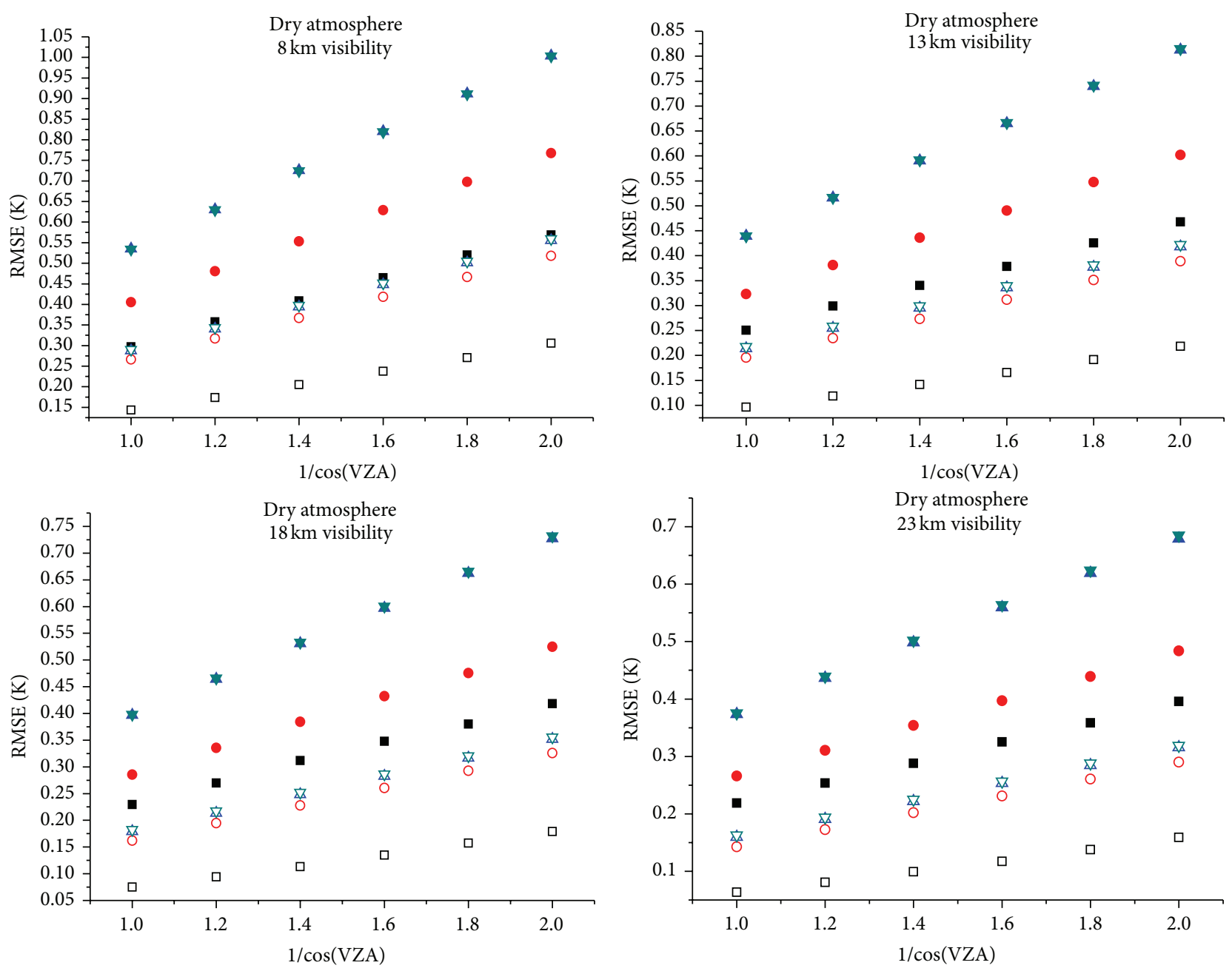

$$
\begin{aligned}
& \text { - } \square 295 \mathrm{~K}<\mathrm{LST}<315 \mathrm{~K} \Delta \triangle 255 \mathrm{~K}<\mathrm{LST}<285 \mathrm{~K} \\
& \text { - } \circ 280 \mathrm{~K}<\mathrm{LST}<300 \mathrm{~K} \nabla \nabla 255 \mathrm{~K}<\mathrm{LST}<315 \mathrm{~K}
\end{aligned}
$$

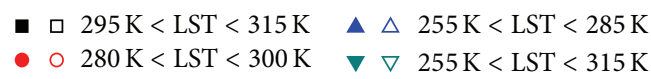

FIGURE 8: RMSE of LST retrieval for grass under wet and dry atmospheres with different visibility (hollow circles for Algorithm 1 and solid circles for Algorithm 2).

To analyze the influence of AOD on TOA BT, the simulated data with various visibilities under the six VZAs is used. For a certain aerosol type and surface type (grass or soil), the differences $(\triangle \mathrm{BT})$ between the aerosolcontaminated $\left(\mathrm{BT}_{\text {visibility }=3,8,13,18 \mathrm{~km}}\right)$ TOA BT and aerosolfree $\left(\mathrm{BT}_{\text {visibility }=23 \mathrm{~km}}\right)$ TOA BT are calculated under dry (WVC: $0-1.5 \mathrm{~g} / \mathrm{cm}^{2}$ ) and wet (WVC: $4-5.5 \mathrm{~g} / \mathrm{cm}^{2}$ ) atmospheres, respectively. Generally, we can expect such factors to affect TOA BT in different channels. As an example, for urban aerosol type, the $\Delta \mathrm{BT}$ caused by different visibilities under wet and dry atmosphere for soil surface are given in Figures 5 and 6 , respectively. It is noted that the $\Delta \mathrm{BT}$ is highly variable, and the AOD effect is much more serious in MIR channels (AHS CH66 and CH68) than that in TIR channels (AHS CH75 and CH79) due to the wavelength dependence of the aerosol scattering. Moreover, AOD under dry atmosphere causes much more TOA BT variation than that under wet atmosphere, since in case of a wet atmosphere the spectrum is dominated by water vapour and hence the aerosol does not play such a dominant role. It is noted that the $\triangle \mathrm{BT}$ for AHS CH66 and $\mathrm{CH} 68$ is proportional to the increase of VZA, while inversely for AHS CH75 and CH79; for urban aerosol, $\mathrm{AOD}$ mostly produce positive $\triangle \mathrm{BT}$ under wet or dry atmosphere.

In addition, the effect of aerosol type on TOA BT is investigated in terms of three typical aerosol types, namely, rural, urban, and tropospheric aerosols, under six VZAs with a visibility of $23 \mathrm{~km}$, and the TOA BT differences under two different aerosol types are calculated. It is found that the TOA BT variation caused by aerosol type is much lower than that caused by AOD, especially for dry atmosphere. As an example, BT differences for soil surface under wet atmosphere is given in Figure 7, and an attenuation within $1.0 \mathrm{~K}$ is presented in channel 66 , while the aerosol type almost produce slight attenuation on TOA BT in channel 79 among these three aerosol type. Therefore, as following, its effect on LST retrieval is not discussed, and only AOD is focused. 

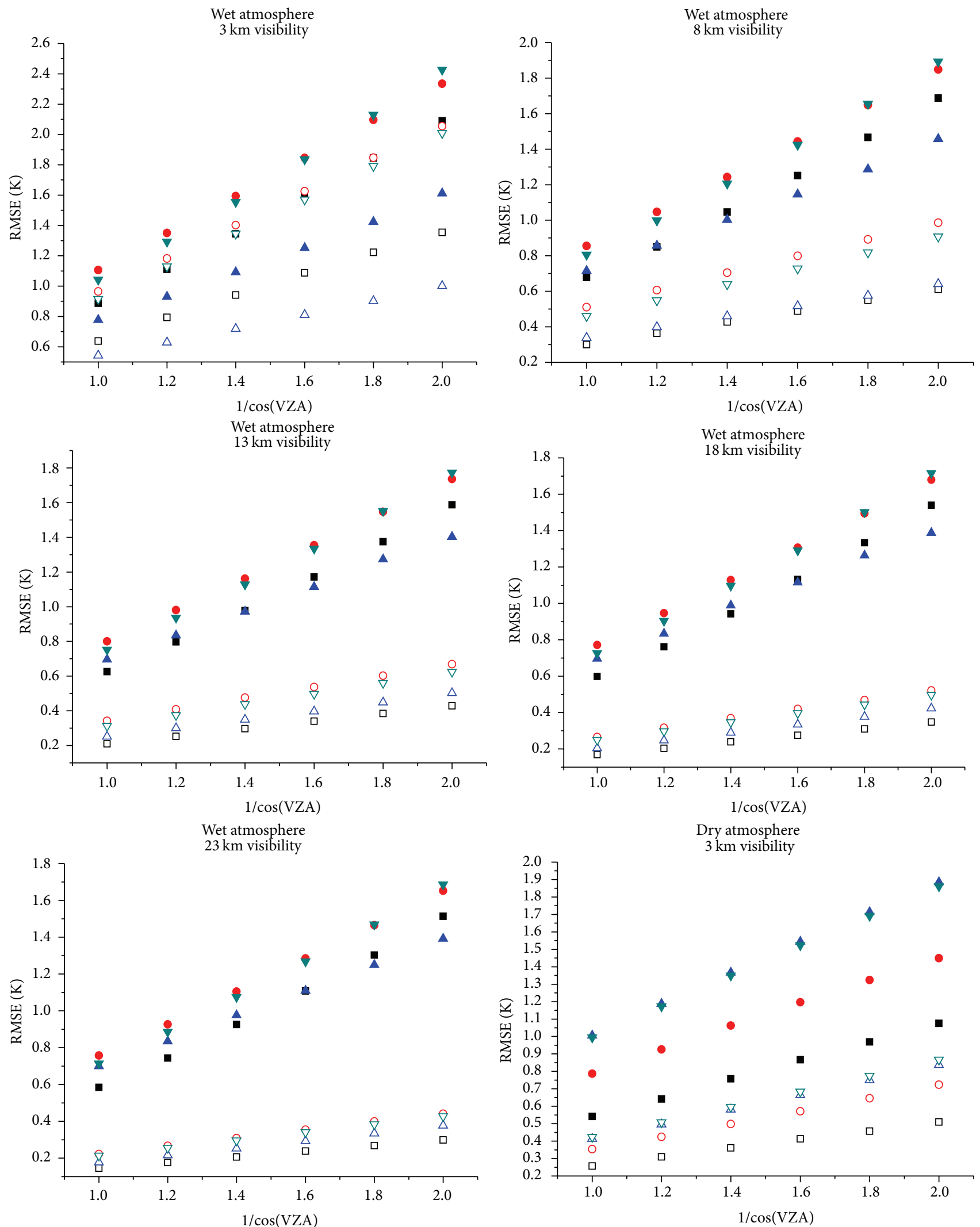

- $\square 295 \mathrm{~K}<\mathrm{LST}<315 \mathrm{~K} \Delta \triangle 255 \mathrm{~K}<\mathrm{LST}<285 \mathrm{~K}$

- $\circ 280 \mathrm{~K}<\mathrm{LST}<300 \mathrm{~K} \nabla \nabla 255 \mathrm{~K}<\mathrm{LST}<315 \mathrm{~K}$

- $\square 295 \mathrm{~K}<\mathrm{LST}<315 \mathrm{~K} \Delta \triangle 255 \mathrm{~K}<\mathrm{LST}<285 \mathrm{~K}$

- $\circ 280 \mathrm{~K}<\mathrm{LST}<300 \mathrm{~K} \nabla \nabla 255 \mathrm{~K}<\mathrm{LST}<315 \mathrm{~K}$

FIGURE 9: Continued. 

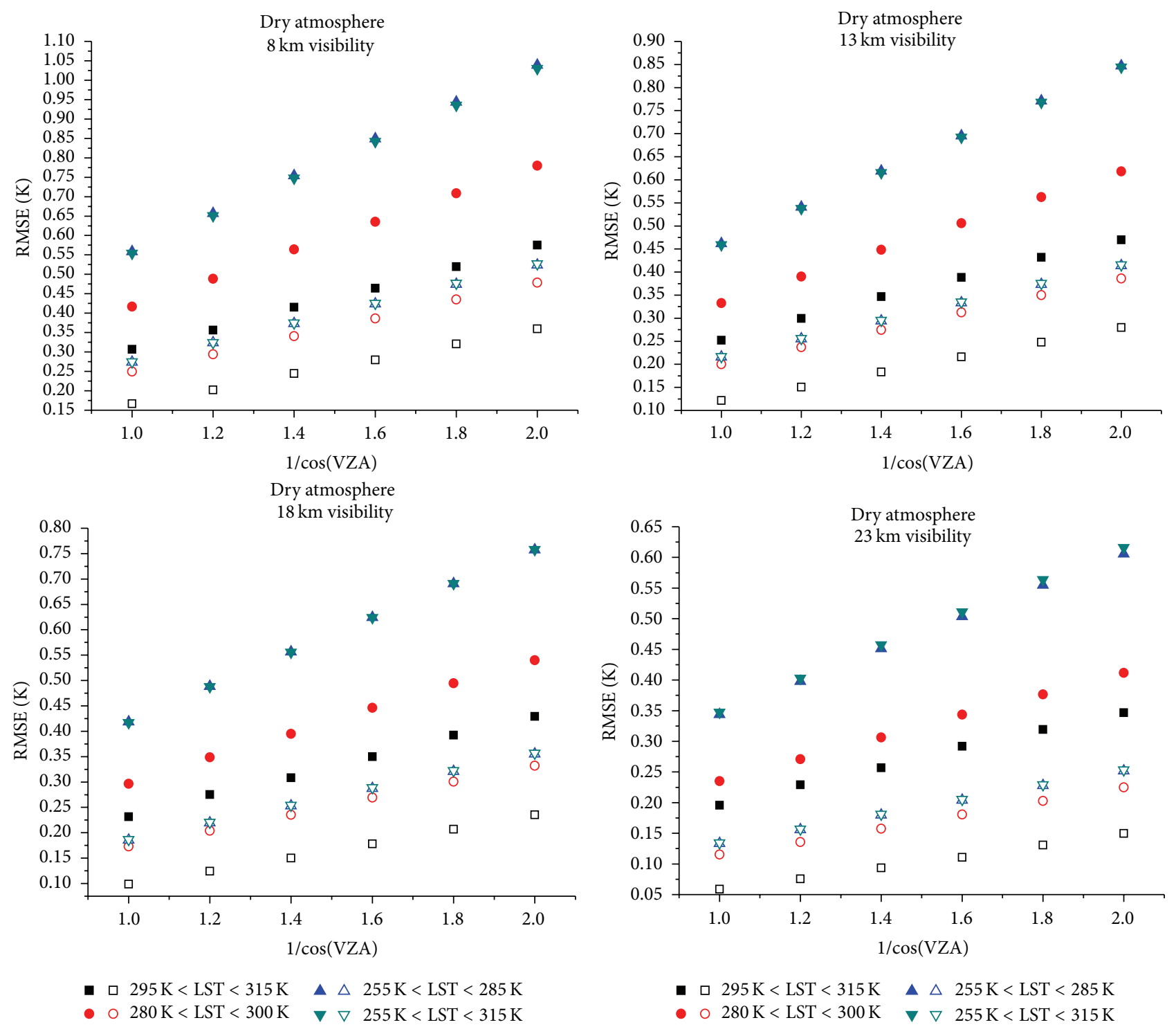

Figure 9: The same legend as that of Figure 8, but for soil.

5.1.2. The Effect of Aerosol on LST Retrieval. As described above, aerosol could produce a great influence on TOA BT, especially for MIR channels, which will directly affect LST retrieval accuracy. However, few studies have addressed the problem of aerosol effect in the existing LST retrieval algorithms, even if the aerosol loading retrieval algorithms from the remote sensing data have been developing for many years. In this section, the LST retrieval accuracies of Algorithm 1 and Algorithm 2 under various atmosphere and visibility conditions are investigated with simulated data.

For urban aerosol type, the root mean square errors (RMSEs) of LST retrieval with Algorithm 1 and Algorithm 2 are calculated under various VZAs, five visibilities $(3,8,13,18$, and $23 \mathrm{~km}$ ), two types of atmosphere (wet and dry), and two land surfaces (grass and soil) (see Figures 8 and 9). It is worth noting that both Algorithm 1 and Algorithm 2 are affected by aerosol when visibility is lower than $8 \mathrm{~km}$; Algorithm 2 still presents lower RMSE than Algorithm 1, especially for wet atmosphere; when the VZA is equal to $60^{\circ}$ and visibility is equal to $3 \mathrm{~km}$, Algorithm 1 presents a maximal RMSE of approximately $2.3 \mathrm{~K}$, while Algorithm 2 presents $1.5 \mathrm{~K}$; RMSE of approximately $1.0 \mathrm{~K}$ is increased when visibility varies from $3 \mathrm{~km}$ to $23 \mathrm{~km}$; the RMSE for soil is $0.2 \mathrm{~K}$ higher than that for grass.

5.2. Uncertainty Analysis under Aerosol Contaminated Condition. LSE, atmospheric correction error, the instrument noise, and the accuracy of the algorithm itself, and so forth affect the accuracy of LST retrieval. To analyze the uncertainty of LST retrieval under aerosol contaminated condition, a sensitivity analysis in terms of the uncertainties of LSE, WVC, and instrument noise under $3 \mathrm{~km}$ and $23 \mathrm{~km}$ visibility is performed for Algorithm 1 and Algorithm 2 using the simulated data with a VZA of $0^{\circ}$ to eliminate VZA effect. 


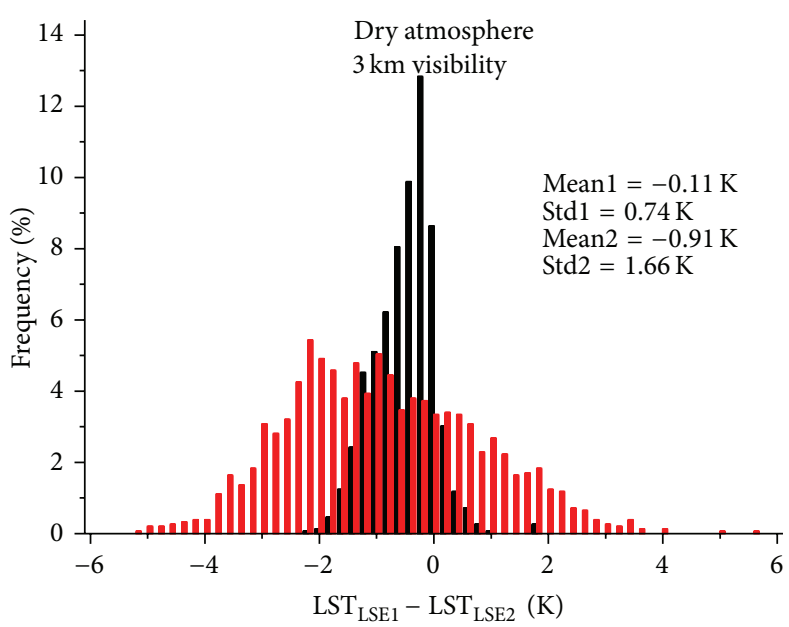

(a)

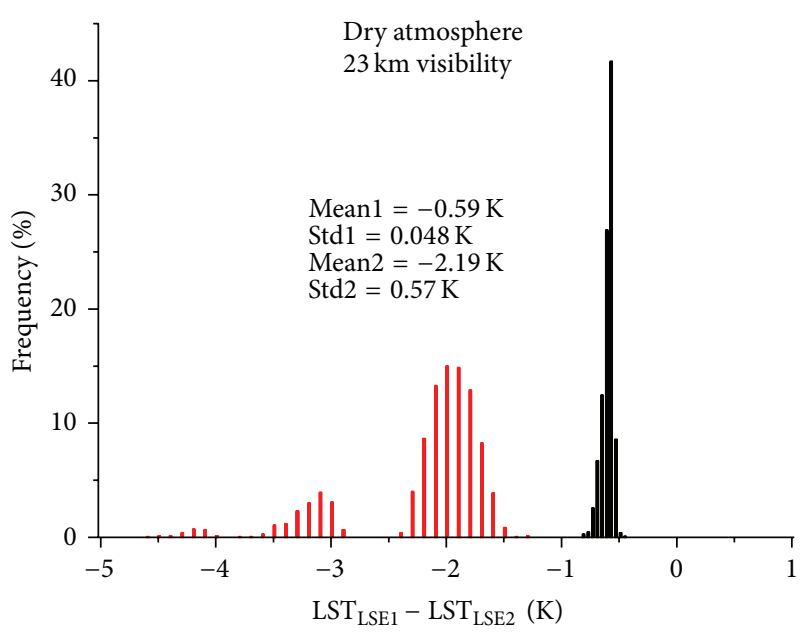

Algorithm 1 Algorithm 2

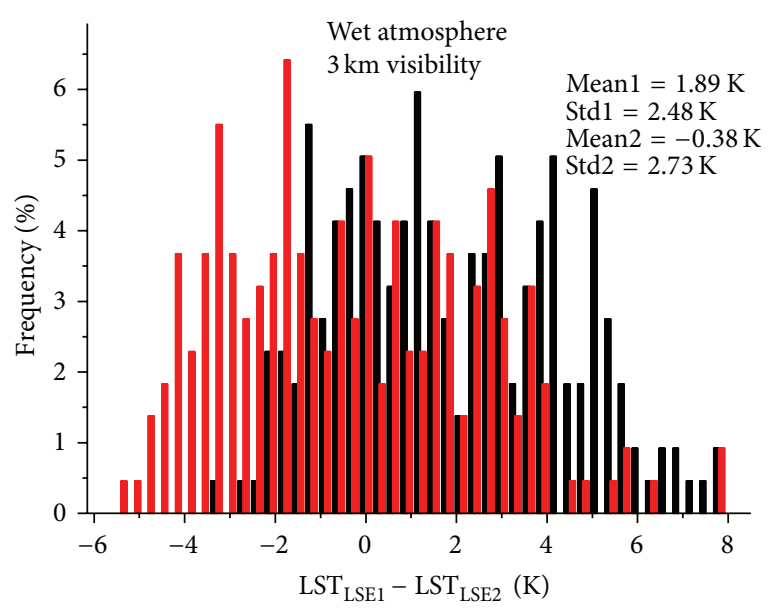

(b)

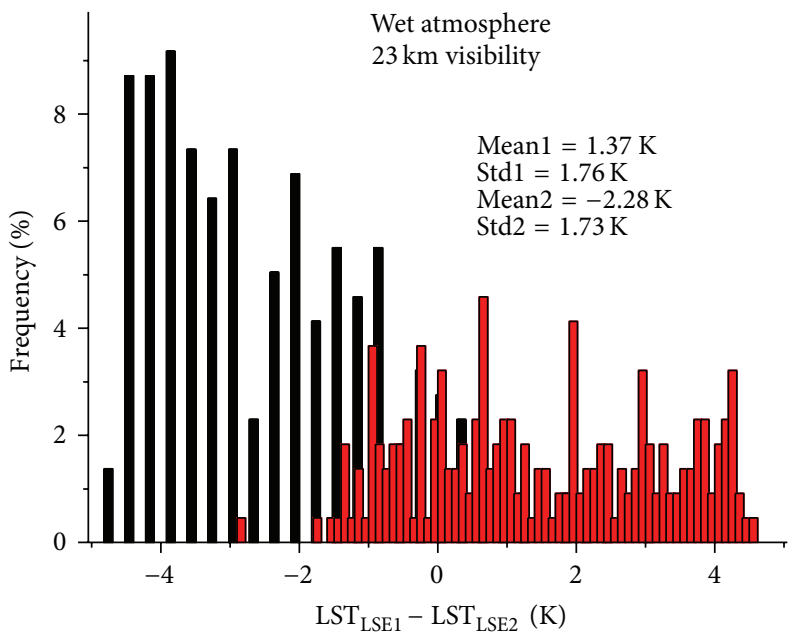

Algorithm 1 Algorithm 2

(c)

(d)

FIGURE 10: Histogram of the LST error due to the uncertainty in LSE at VZA $=0^{\circ}$ when visibility $=3 \mathrm{~km}$ and $23 \mathrm{~km}$, respectively. $\mathrm{LST}_{\mathrm{LSE1}}$ and $\mathrm{LST}_{\mathrm{LSE2}}$ are the LSTs retrieved using (3) or (4) for the cases where the soil is misclassified into grass and for the original LSE, respectively.

5.2.1. The Sensitivity to Uncertainty of LSE. The LST retrieval algorithms depend on an accurate knowledge of land surface types since the LSE is acquired by classification in this paper. The largest LST uncertainty would be induced by misclassifying soil into grass, and the LST with error-added LSE for soil (denoted as LST $_{\text {LSE1 }}$ ) is retrieved with the coefficients for grass. Under dry and wet atmospheres, the LST error caused by LSE uncertainty is expressed by the differences between $\mathrm{LST}_{\mathrm{LSE1}}$ and the error-free LST (denoted as $\mathrm{LST}_{\mathrm{LSE} 2}$ ) retrieved with the right coefficients (see Figure 10) when the visibility is equal to $3 \mathrm{~km}$ and $23 \mathrm{~km}$, respectively. It is demonstrated that the LST error caused by the uncertainty of LSE under wet atmosphere is larger than that under dry atmosphere, and Algorithm 2 is more sensitive to the misclassification than Algorithm 1 due to large variation of LSE in MIR channels. Furthermore, the standard deviation of LST error under $3 \mathrm{~km}$ visibility is larger than that under $23 \mathrm{~km}$ visibility; under $3 \mathrm{~km}$ and $23 \mathrm{~km}$ visibility, for Algorithm 1, the LST error caused by the misclassification is approximately within $1.0 \mathrm{~K}$ under dry atmosphere, while more than $2.0 \mathrm{~K}$ under wet atmosphere; for Algorithm 2, this error is more than $2.0 \mathrm{~K}$ under various atmosphere conditions.

5.2.2. The Sensitivity to Uncertainty of WVC. For some channels in the infrared atmospheric window, the main atmospheric effect comes from water vapor absorption and has important effect to LST retrieval error. In this study, the atmospheric WVC is used to select the coefficients in (3) and (4). The WVC error may result in wrong subrange selection and subsequently lead to a large error in the retrieved LST. This is also one of the reasons for two consecutive WVC subranges overlapping by $0.5 \mathrm{~g} / \mathrm{cm}^{2}$ in the algorithm development. For example, the WVC $\in\left[1.0,1.5 \mathrm{~g} / \mathrm{cm}^{2}\right]$ falling into two subranges WVC $\in\left[0,1.5 \mathrm{~g} / \mathrm{cm}^{2}\right]$ and WVC 


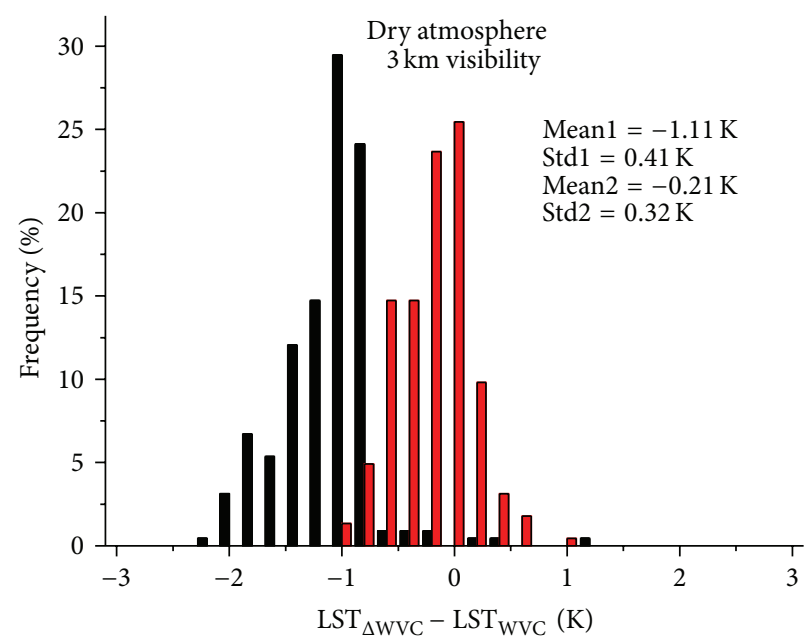

(a)

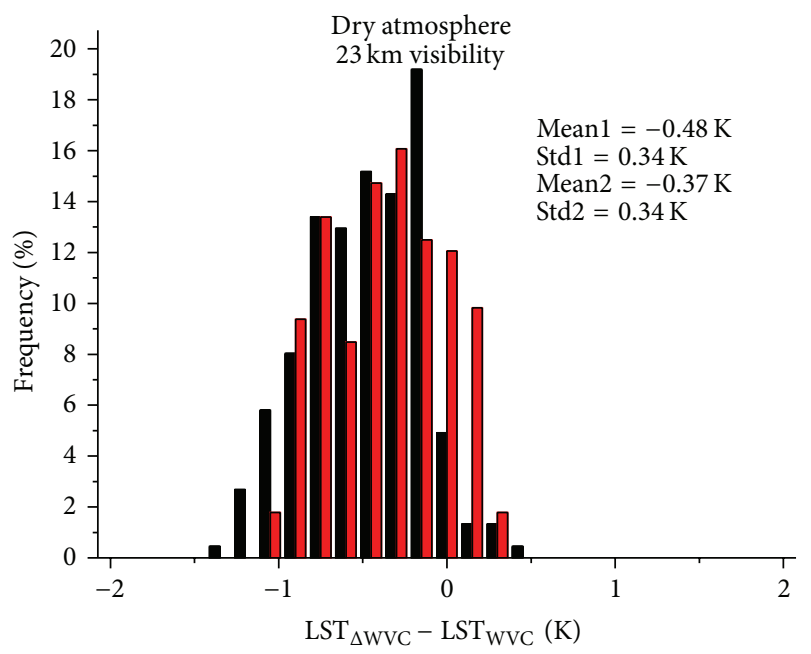

Algorithm 1

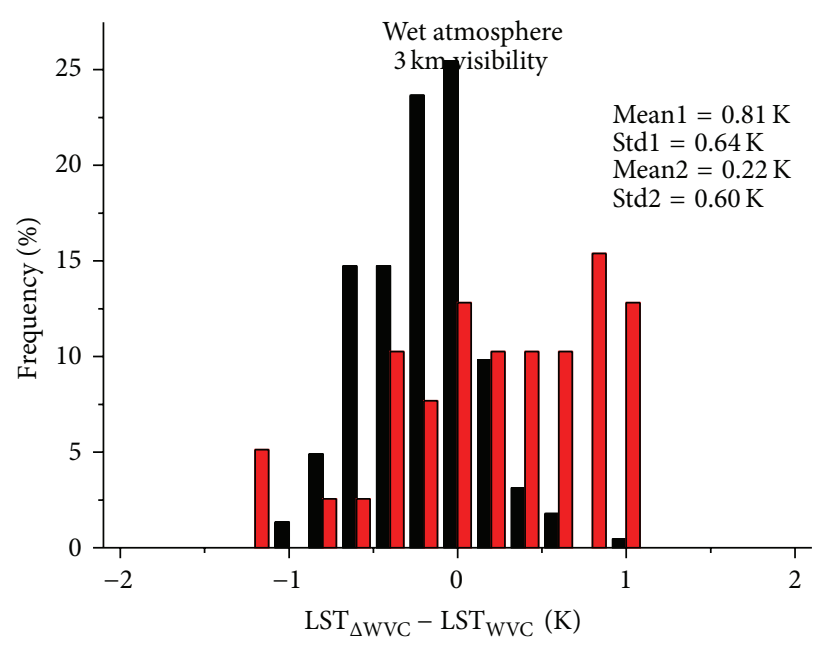

(b)

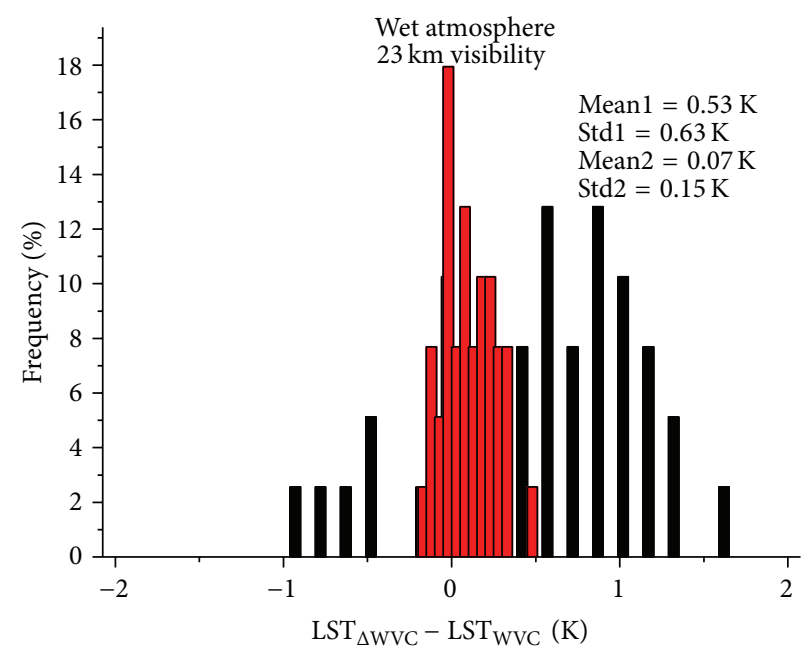

Algorithm 1

Algorithm 2

(c)

(d)

FIGURE 11: Histogram of the LST error due to the uncertainty in WVC at VZA $=0^{\circ}$ when visibility $=3 \mathrm{~km}$ and $23 \mathrm{~km}$, respectively. $\mathrm{LST}_{\triangle \mathrm{WVC}}$ and $\mathrm{LST}_{\mathrm{WVC}}$ are the LSTs retrieved using (3) or (4) for the case where the WVC was increased by $20 \%$ and for the original WVC, respectively.

$\epsilon\left[1.0,2.5 \mathrm{~g} / \mathrm{cm}^{2}\right]$; thus, the retrieved LSTs (LST ${ }_{\Delta \mathrm{WVC}}$ ) using the coefficients of the subrange with WVC $\in\left[0,1.5 \mathrm{~g} / \mathrm{cm}^{2}\right]$ and $T_{s} \in[290 \mathrm{~K}, 310 \mathrm{~K}]$ are different from the retrieved LSTs ( $\mathrm{LST}_{\mathrm{WVC}}$ ) using the coefficients of the subrange with WVC $\epsilon$ $\left[1.0,2.5 \mathrm{~g} / \mathrm{cm}^{2}\right], T_{s} \in[290 \mathrm{~K}, 310 \mathrm{~K}]$. In order to characterize the WVC error on the LST retrieval, an error of $20 \%$ is added to original WVC to generate the error-added WVC, which is then used to select the coefficients in (3) and (4), and the simulated data with the overlap WVC are used to estimate the LST with different coefficients of the two adjacent subranges. The histograms of the LST difference between them $\left(\mathrm{LST}_{\Delta \mathrm{WVC}}-\mathrm{LST}_{\mathrm{WVC}}\right)$ for dry and wet atmospheres with a visibility of $3 \mathrm{~km}$ and $23 \mathrm{~km}$, respectively, are shown in Figure 11. It is noted that Algorithm 1 is more sensitive to the uncertainty of WVC than Algorithm 2; under $3 \mathrm{~km}$ or $23 \mathrm{~km}$ visibility, LST error caused by a WVC uncertainty of $20 \%$ is within $1.5 \mathrm{~K}$ for Algorithm 1, and within $0.8 \mathrm{~K}$ for Algorithm 2 ; in most cases, the LST errors under $3 \mathrm{~km}$ visibility is a little larger than those under $23 \mathrm{~km}$ visibility.

5.2.3. The Sensitivity to Instrument Noise. The expected radiometric noise of AHS CH66, 68, 75, and 79 is $0.33 \mathrm{~K}$, $0.33,0.2 \mathrm{~K}$, and $0.2 \mathrm{~K}$, respectively. In order to analyze the instrument noise effect on LST retrieval, the corresponding instrument radiometric noises for these channels are added to their TOA BT; then, the noised LST ( $\mathrm{LST}_{\mathrm{NE} \triangle \mathrm{T}}$ ) is estimated again using Algorithm 1 and Algorithm 2, respectively. The differences $(\delta(\mathrm{LST}))$ between noise-free $\left(\mathrm{LST}_{\mathrm{nf}}\right)$ and $\mathrm{LST}_{\mathrm{NE} \Delta \mathrm{T}}$ are calculated for dry and wet atmosphere with a visibility of $3 \mathrm{~km}$ and $23 \mathrm{~km}$, respectively, and the corresponding histograms are shown in Figure 12. It can be found that the $\delta$ (LST) for Algorithm 2 is a little higher than that 


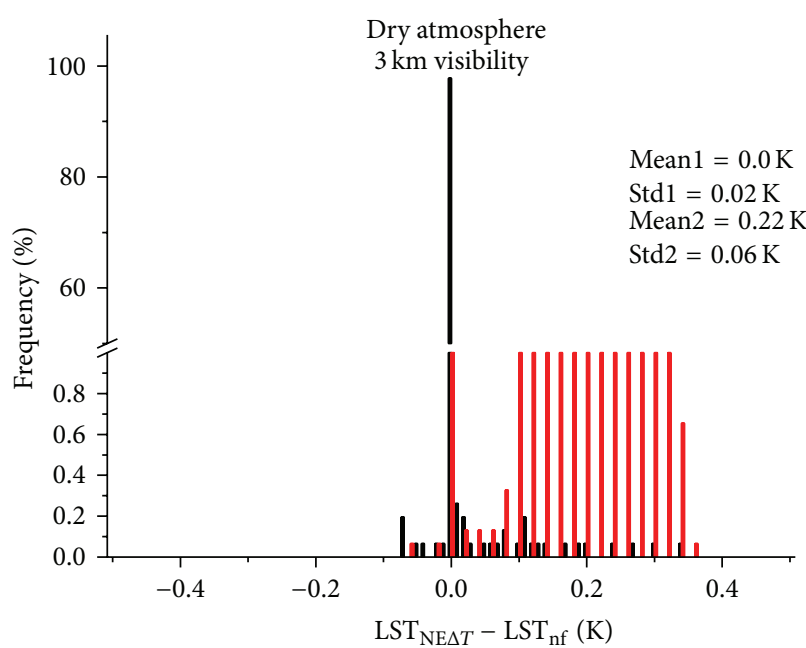

(a)

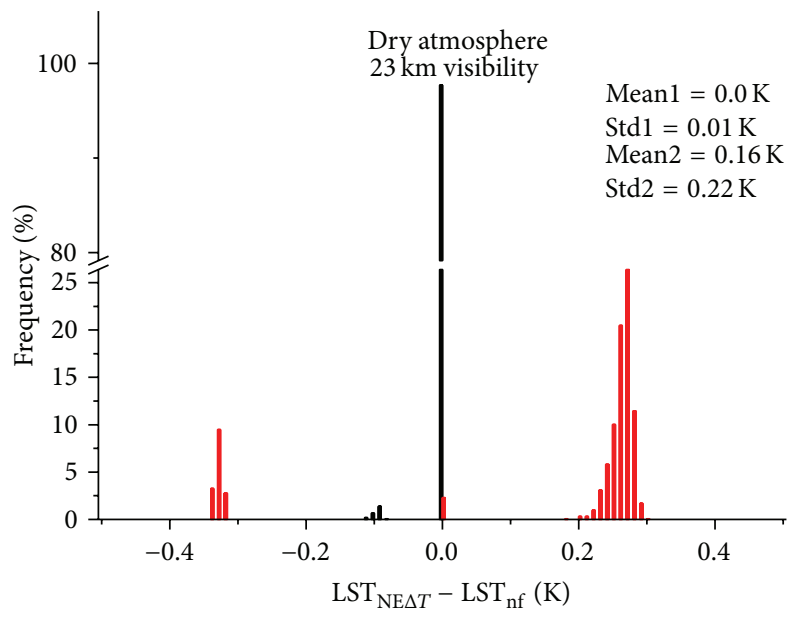

Algorithm 1 Algorithm 2

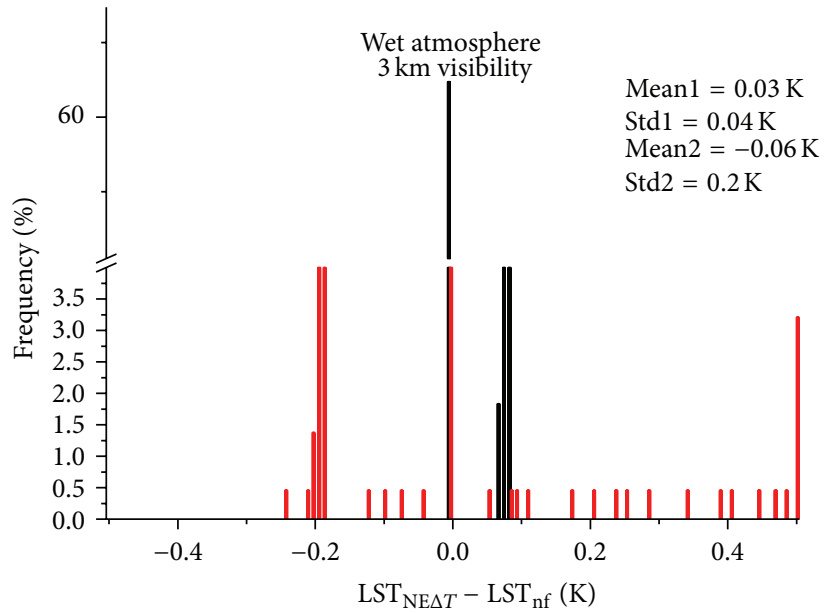

(b)

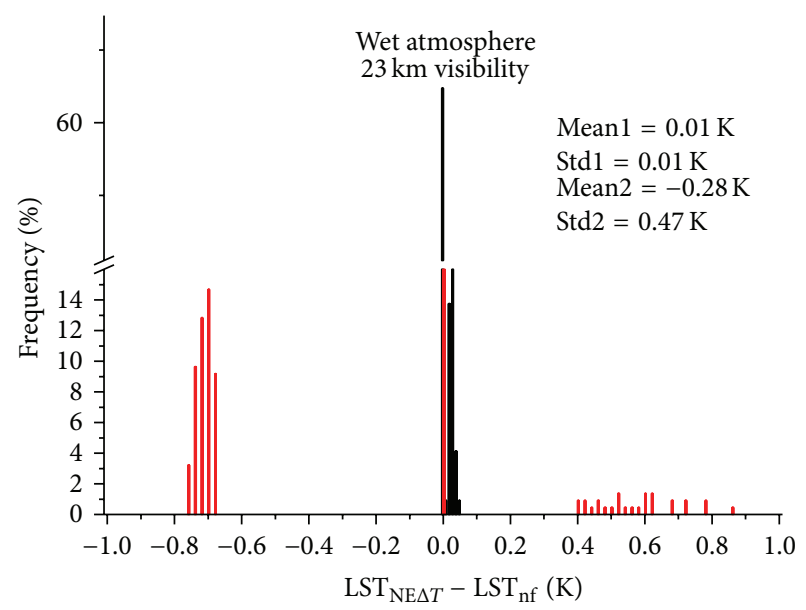

Algorithm 1

Algorithm 2

(c)

(d)

FIGURE 12: Histogram of the LST error caused by the instrument noise (NE $\Delta \mathrm{T})$ at VZA $=0^{\circ}$, where LST NE$\Delta \mathrm{T}_{\text {and LST }}$ are the LSTs retrieved using (3) or (4) with the instrument noise-added and for the case of noise-free brightness temperatures, respectively.

for Algorithm 1 since the higher instrument noise would produce when more channels are used to retrieved LST; the maximum standard deviation of $\delta(\mathrm{LST})$ for Algorithm 2 is approximately $0.5 \mathrm{~K}$, while it is $0.04 \mathrm{~K}$ for Algorithm 1 under various atmosphere and visibility conditions.

\section{Conclusion and Summary}

This paper has addressed an analysis of aerosol effect on LST retrieval using two methods with the data simulated with MODTRAN model derived by cloud-free TIGR atmosphere profiles, various land surface conditions (LSE and LST), VZAs, and spectral response functions. The analysis results show that, under various AOD conditions, Algorithm 2 presents higher LST retrieval accuracy than Algorithm 1, with a maximal RMSE of approximately $2.3 \mathrm{~K}$ for Algorithm 1 and $1.5 \mathrm{~K}$ for Algorithm 2 when the VZA is equal to $60^{\circ}$ and visibility is equal to $3 \mathrm{~km}$. Besides, LST retrieval accuracy would be reduced by approximately $1.0 \mathrm{~K}$ when visibility varying from $3 \mathrm{~km}$ to $23 \mathrm{~km}$.

Furthermore, an analysis under two typical AOD (visibility $=3 \mathrm{~km}$ and $23 \mathrm{~km}$ ) is performed in terms of uncertainties of LSE, WVC and instrument noise with simulated data. The analysis results show that the Algorithm 2 is more sensitive to LSE than that for Algorithm 1 due to large variation of LSE in MIR channel. When soil is misclassified into grass, the LST error for Algorithm 1 is within $1.0 \mathrm{~K}$, and more than $2.0 \mathrm{~K}$ under dry and wet atmosphere, respectively; this error for Algorithm 2 is more than $2.0 \mathrm{~K}$ under various atmosphere conditions. In addition, a WVC uncertainty of $20 \%$ would introduce a LST error within $1.5 \mathrm{~K}$ for Algorithm 1 and within $0.8 \mathrm{~K}$ for Algorithm 2. The maximum standard deviation of the LST error caused by the instrument noise is approximately $0.5 \mathrm{~K}$ for Algorithm 2, while it is $0.04 \mathrm{~K}$ for Algorithm 1 . 
In summary, aerosol indeed produces influence on LST retrieval, and Algorithm 2 integrating MIR and TIR channels presents lower RMSE than Algorithm 1, especially under low visibility condition, which would be benefit to developing an aerosol correction algorithm for LST retrieval. However, due to the larger variation in LSE for MIR channels, Algorithm 2 is more sensitive to LSE than Algorithm 1, so Algorithm 2 could be used effectively with the accurate knowledge of LSE.

\section{Conflict of Interests}

The authors declare that there is no conflict of interests regarding the publication of this paper.

\section{Acknowledgments}

This work has been supported by the National Natural Science Foundation of China under Grants 41301387 and 41371353. The authors would like to thank anonymous reviewers for the valuable comments and suggestions.

\section{References}

[1] H. Mannstein, "Surface energy budget, surface temperature, and thermal inertia," in Remote Sensing Applications in Meteorology and Climatology, R. A. Vaughan and D. Reidel, Eds., vol. 201, pp. 391-410, A Reidel Publishing Company, Dordrecht, The Netherlands, 1987.

[2] Z.-L. Li, B.-H. Tang, H. Wu et al., "Satellite-derived land surface temperature: current status and perspectives," Remote Sensing of Environment, vol. 131, pp. 14-37, 2013.

[3] Y. H. Kerr, J. P. Lagouarde, F. Nerry, and C. Ottlé, "Land surface temperature retrieval techniques and applications," in Thermal Remote Sensing in Land Surface Processes, D. A. Quattrochi and J. C. Luvall, Eds., pp. 33-109, CRC Press, Boca Raton, Fla, USA, 2004.

[4] L. Zhong, Y. Ma, Z. Su, and M. S. Salama, "Estimation of land surface temperature over the Tibetan Plateau using AVHRR and MODIS data," Advances in Atmospheric Sciences, vol. 27, no. 5, pp. 1110-1118, 2010.

[5] P. Dash, F.-M. Göttsche, F.-S. Olesen, and H. Fischer, "Land surface temperature and emissivity estimation from passive sensor data: theory and practice-current trends," International Journal of Remote Sensing, vol. 23, no. 13, pp. 2563-2594, 2002.

[6] J. C. Price, "Estimating surface temperatures from satellite thermal infrared data-a simple formulation for the atmospheric effect," Remote Sensing of Environment, vol. 13, no. 4, pp. 353361, 1983.

[7] J. Susskind, J. Rosenfield, D. Reuter, and M. T. Chahine, "Remote sensing of weather and climate parameters from HIRS2/MSU on Tiros-N," Journal of Geophysical Research, vol. 89, no. 3, pp. 4677-4697, 1984.

[8] F. Becker and Z.-L. Li, "Towards a local split window method over land surfaces," International Journal of Remote Sensing, vol. 11, no. 3, pp. 369-393, 1990.

[9] J. Sobrino, C. Coll, and V. Caselles, "Atmospheric correction for land surface temperature using NOAA-11 AVHRR channels 4 and 5," Remote Sensing of Environment, vol. 38, no. 1, pp. 19-34, 1991.
[10] Y. H. Kerr, J. P. Lagouarde, and J. Imbernon, "Accurate land surface temperature retrieval from AVHRR data with use of an improved split window algorithm," Remote Sensing of Environment, vol. 41, no. 2-3, pp. 197-209, 1992.

[11] F. Becker and Z.-L. Li, "Surface temperature and emissivity at various scales: definition, measurement and related problems," Remote Sensing Reviews, vol. 12, no. 3-4, pp. 225-253, 1995.

[12] C. Coll, T. J. Schmugge, and S. J. Hook, "Atmospheric effects on the temperature emissivity separation algorithm," in Europto Conference on Remote Sensing for Agriculture, Ecosystems, and Hydrology, vol. 3499 of Proceedings of SPIE, pp. 405-415, September 1998.

[13] A. Gillespie, S. Rokugawa, T. Matsunaga, J. S. Cothern, S. Hook, and A. B. Kahle, "A temperature and emissivity separation algorithm for advanced spaceborne thermal emission and reflection radiometer (ASTER) images," IEEE Transactions on Geoscience and Remote Sensing, vol. 36, no. 4, pp. 1113-1126, 1998.

[14] D. Sun and R. T. Pinker, "Estimation of land surface temperature from a Geostationary Operational Environmental Satellite (GOES-8)," Journal of Geophysical Research D: Atmospheres, vol. 108, article 4326, no. 11, 2003.

[15] N. Baker and H. Kilcoyne, Joint Polar Satellite System (JPSS) VIIRS Land Surface Temperature Algorithm Theoretical Basis Document, Goddard Space Flight Center, Greenbelt, Md, USA, 2011.

[16] N. R. Nalli and L. L. Stowe, "Aerosol correction for remotely sensed sea surface temperatures from the National Oceanic and Atmospheric Administration advanced very high resolution radiometer," Journal of Geophysical Research C: Oceans, vol. 107, no. 10, pp. 36-1-36-18, 2002.

[17] R. G. Driggers, Encyclopedia of Optical Engineering, Marcel Dekker, New York, NY, USA, 2003.

[18] S. J. Brown, A. R. Harris, I. M. Mason, and A. M. Závody, “New aerosol robust sea surface temperature algorithms for the alongtrack scanning radiometer," Journal of Geophysical Research C: Oceans, vol. 102, no. 13, pp. 27973-27989, 1997.

[19] C. J. Merchant, A. R. Harris, M. J. Murray, and A. M. Závody, "Toward the elimination of bias in satellite retrievals of sea surface temperature 1 . Theory, modeling and interalgorithm comparison," Journal of Geophysical Research C: Oceans, vol. 104, no. 10, pp. 23565-23578, 1999.

[20] D. A. May, L. L. Stowe, J. D. Hawkins, and E. P. McClain, "A correction for Saharan dust effects on satellite sea surface temperature measurements," Journal of Geophysical Research, vol. 97, no. 3, pp. 3611-3619, 1992.

[21] C. J. Merchant, O. Embury, P. le Borgne, and B. Bellec, "Saharan dust in nighttime thermal imagery: detection and reduction of related biases in retrieved sea surface temperature," Remote Sensing of Environment, vol. 104, no. 1, pp. 15-30, 2006.

[22] T. Blackmore, A. O'Carroll, K. Fennig, and R. Saunders, "Correction of AVHRR Pathfinder SST data for volcanic aerosol effects using ATSR SSTs and TOMS aerosol optical depth," Remote Sensing of Environment, vol. 116, pp. 107-117, 2012.

[23] C. Walton, "Satellite measurement of sea surface temperature in the presence of volcanic aerosols ( Hawaii, Gulf-of-Mexico)," Journal of Climate \& Applied Meteorology, vol. 24, no. 6, pp. 501507, 1985.

[24] F. Becker and Z.-L. Li, "Temperature-independent spectral indices in thermal infrared bands," Remote Sensing of Environment, vol. 32, no. 1, pp. 17-33, 1990. 
[25] K. Lippert, Temperature retrieval approaches for upcoming BIRD data [Ph.D. thesis], Louis Pasteur University, Strasbourg, France, 2000.

[26] A. Fernández-Renau, J. A. Gómez, and E. de Miguel, "The INTA-AHS system," in Sensors, Systems, and Next-Generation Satellites IX, vol. 5978 of Proceedings of SPIE, pp. 471-478, September 2005.

[27] J. A. Sobrino, J. C. Jiménez-Muñoz, G. Sòria et al., “Thermal remote sensing in the framework of the SEN2FLEX project: field measurements, airborne data and applications," International Journal of Remote Sensing, vol. 29, no. 17-18, pp. 4961-4991, 2008.

[28] A. Chedin, N. A. Scott, C. Wahiche, and P. Moulinier, "The improved initialization inversion method: a high resolution physical method for temperature retrievals from satellites of the TIROS-N series," Journal of Climate \& Applied Meteorology, vol. 24, no. 2, pp. 128-143, 1985.

[29] F. Chevallier, A. Chédin, F. Chéruy, and J.-J. Morcrette, “TIGRlike atmospheric-profile databases for accurate radiative-flux computation," Quarterly Journal of the Royal Meteorological Society, vol. 126, no. 563, pp. 777-785, 2000.

[30] E. P. Shettle and R. W. Fenn, Models of the Aerosols of the Lower Atmosphere and the Effects of Humidity Variations on Their Optical Properties, AFGLTR-79-0214, 1979.

[31] Z. Wan and J. Dozier, "A generalized split-window algorithm for retrieving land-surface temperature from space," IEEE Transactions on Geoscience and Remote Sensing, vol. 34, no. 4, pp. 892-905, 1996. 

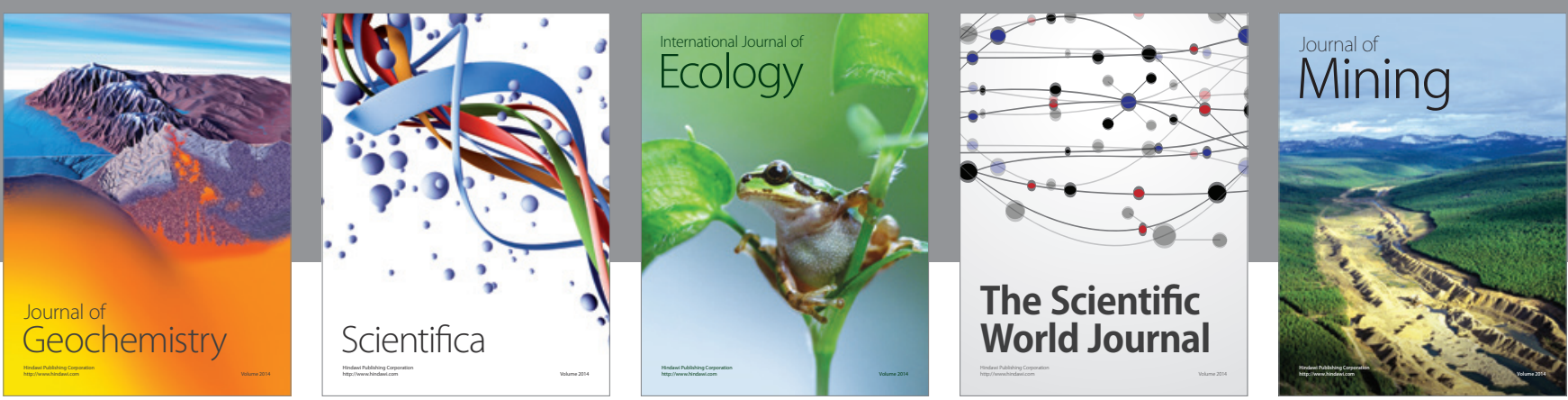

The Scientific World Journal
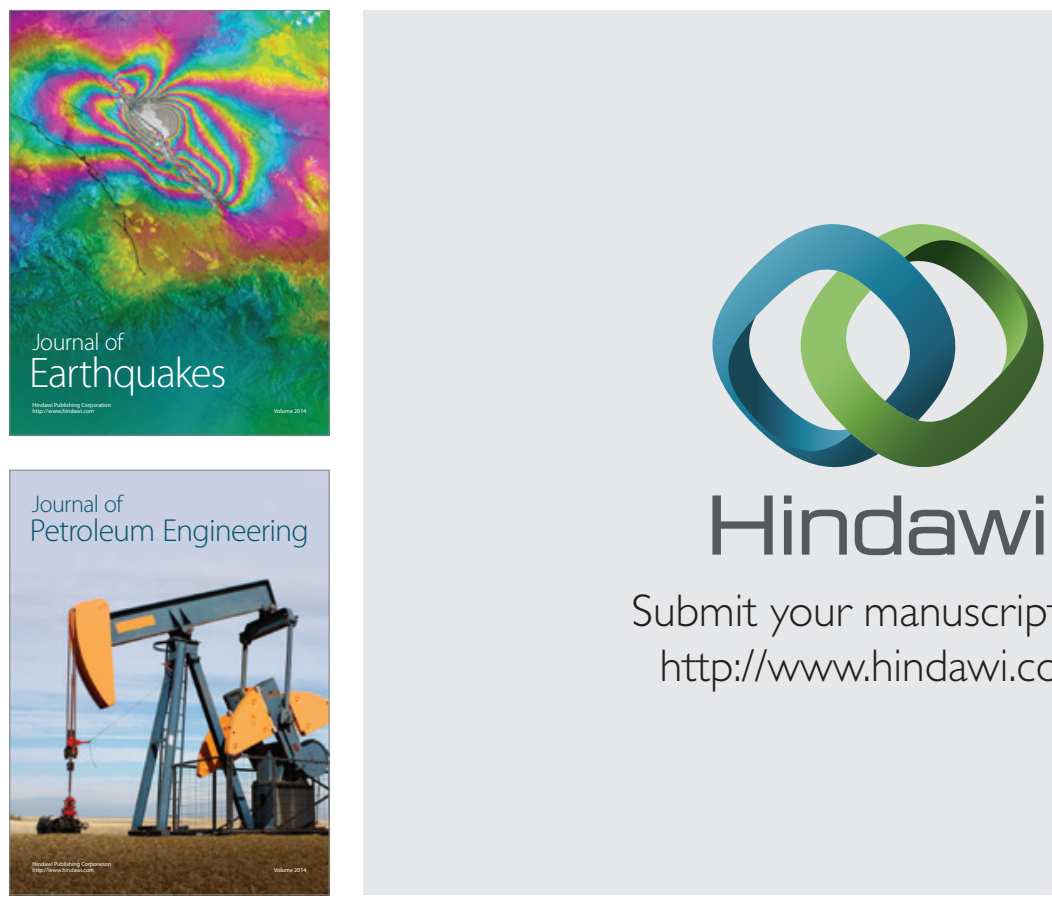

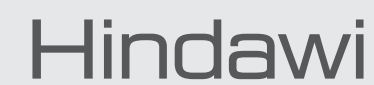

Submit your manuscripts at

http://www.hindawi.com
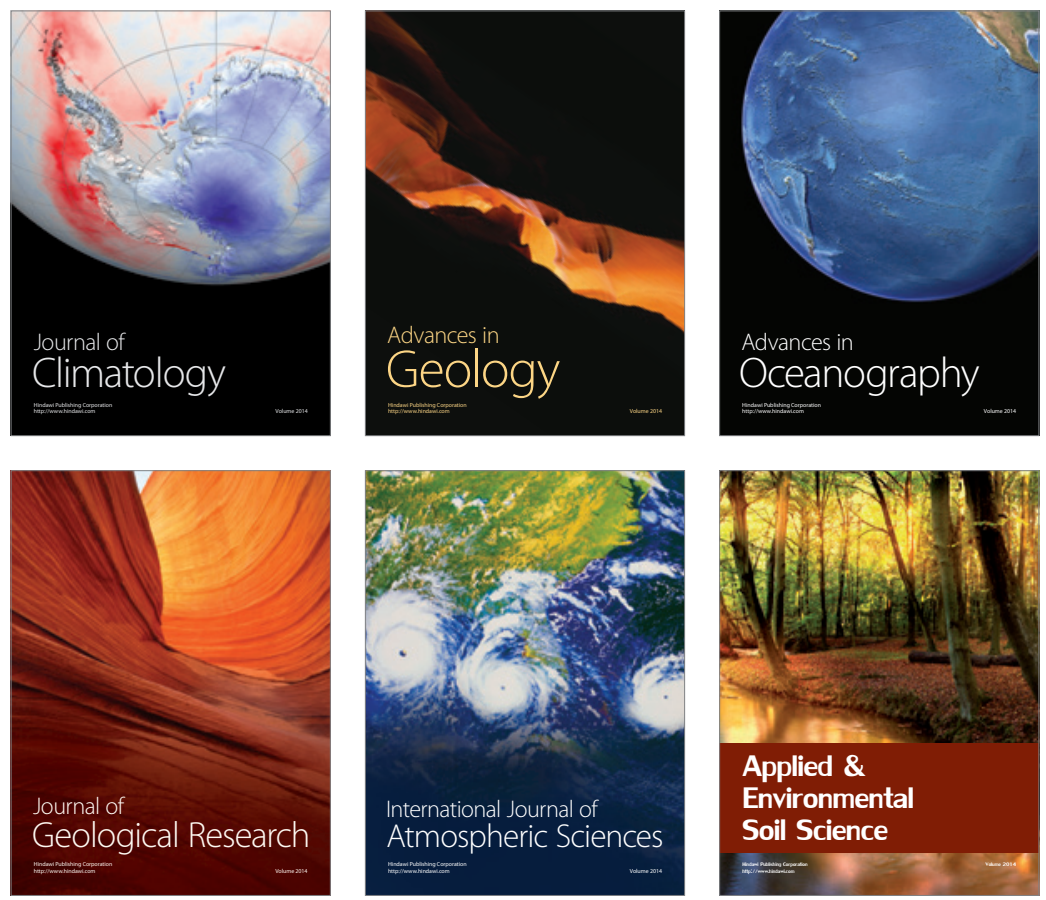
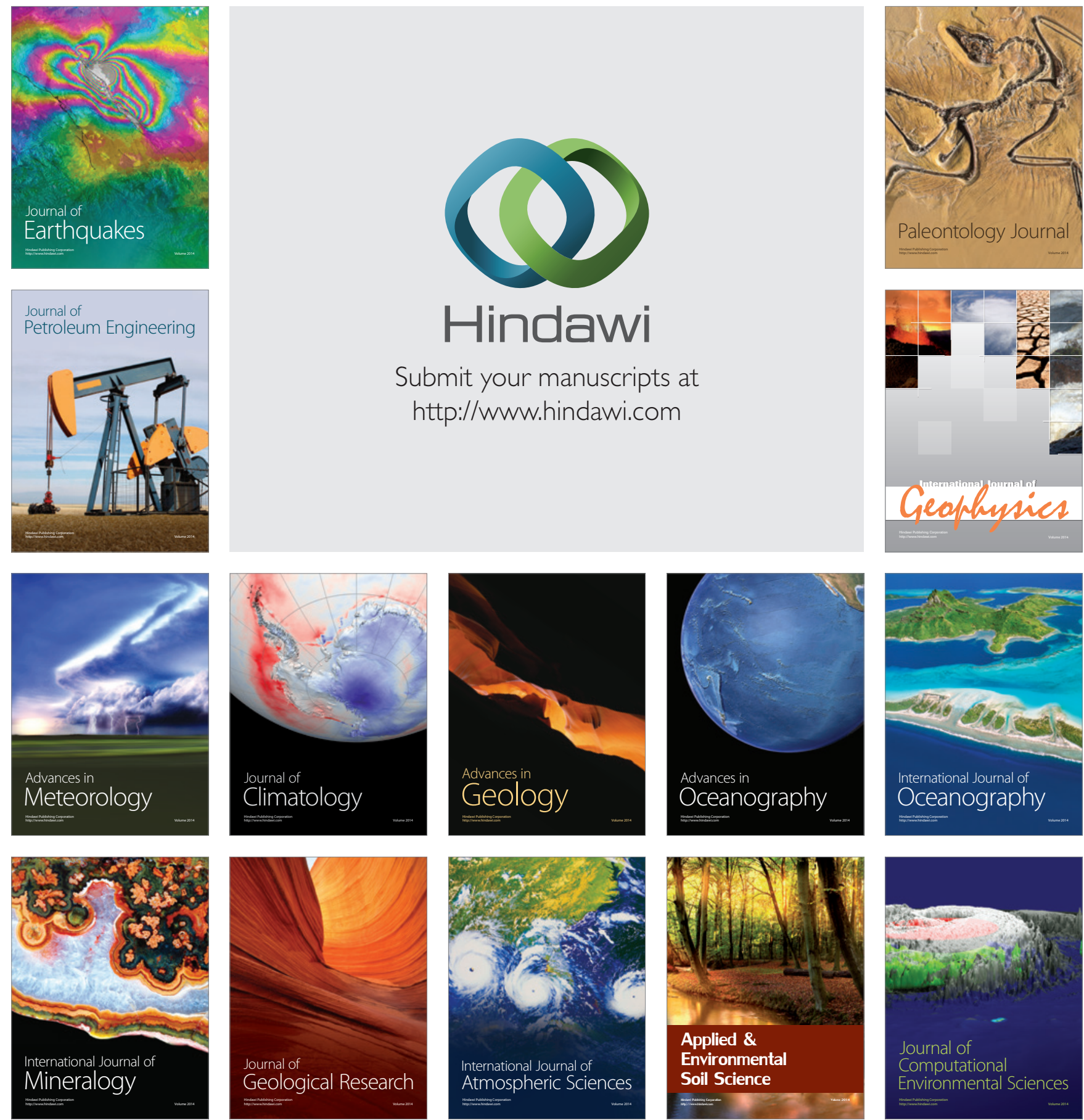